\title{
The Viana footbridge: construction and dynamic monitoring
}

Ricardo Barbosa MSC

Senior Engineer, M. Couto Alves SA (formerly Irmãos Cavaco SA), Guimarães, Portugal

Filipe Magalhães PhD

Assistant Professor, Faculty of Engineering (FEUP), University of Porto, Porto, Portugal
Elsa Caetano PhD

Associate Professor, Faculty of Engineering (FEUP), University of Porto, Porto, Portugal

Álvaro Cunha PhD

Full Professor, Faculty of Engineering (FEUP), University of Porto, Porto, Portugal

A new moveable footbridge was recently built at the entrance of Marina Atlântico in the city of Viana do Castelo, Portugal. This paper presents a brief description of the global solution, with a special focus on the characterisation of the construction methods adopted. Particular consideration is given to the construction of the pivot pylon and the steel structure, showing how all the bridge components work together to ensure a safe working relationship with the marina, the river and users of the continuous bicycling and pedestrian pathway running across the closed bridge. The mechanical, hydraulic, electrical and navigational light systems play fundamental roles, especially during bridge opening and closing operations. Moreover, as this light footbridge is susceptible to vibrations due to human traffic, the paper also describes the dynamic tests performed during and after construction, including two ambient vibration tests, the measurement of cable-stay forces, and tests with groups of pedestrians used to evaluate induced vibration levels along with the monitoring of bridge accelerations over 4 months of use.

\section{Introduction}

In the context of an urban renewal project in the Portuguese city of Viana do Castelo, a new moveable cable-stayed footbridge was built in 2007 over the entrance of the yachting Marina Atlântico so as to extend the existing walking/cycling path located on the north bank of the Lima River. As the bridge had to be located at the entrance of the marina, a structural solution based on a rotating deck supported by a pivot pillar placed in the river was adopted (Figure 1). On the existing slope, steel platforms supported by new piers were built to provide access to the bridge. The two last piers of this path are the delivery, or closing, piers, where the deck endings are supported and locked. The electric wiring and oilhydraulics piping, which provide the motive force of the structure, pass through the deck, cross the pivot pier, and follow the river bottom, finally joining in a control building that houses the switchboards, the hydraulic power pack and the control cabinet, including a touch-screen control panel.

The bridge structure (Figures 2 and 3 ) is composed of a ladder deck, approximately $36 \mathrm{~cm}$ long and $2.5 \mathrm{~m}$ wide, which is suspended by four pairs of cables from a mast. This mast is back-anchored by two pairs of cables in a shorter span $(9 \mathrm{~m})$, from which 11 high-density blocks, with a total mass of $80 \mathrm{t}$, are hung to balance the weight of the longer span. The mast base is welded to a cylinder that accommodates two planetary gear units, each motorised by an hydraulic axial piston motor, and a 3-m diameter wheel gear bearing that allows for rotational movement. The pylon is connected to a massive concrete foundation that provides reaction to the unbalanced moments.

Figure 4 presents photographs of the bridge, showing the two alternative configurations. When the bridge is in use (left image), the vertical and lateral displacements of the two ends of the deck are constrained by their connections to the abutments. When the bridge is opened to allow the entrance of sailing boats into the marina, the main span behaves as a cantilever supported by the pylon and balanced by the concrete counterweight. Further details of the bridge characteristics can be found in Delgado et al. (2008). The authors were involved in the construction, commissioning, testing and temporary monitoring of the Viana footbridge, and the subsequent sections describe some of the most relevant experience gained during that work.

\section{Planning, preparation and workshop fabrication}

\subsection{Pivot pylon}

A geological profile developed from a sampling campaign performed from a floating platform revealed the presence of a superficial sand layer over a granite layer, which led to the designer's proposal - detailed in the unpublished 2005 document, Structural Project of Viana do Castelo Moveable Footbridge, by Lopes et al. (in Portuguese) - to found the pylon on six $600-\mathrm{mm}$ concrete piles (Figure 5). The distance between the access ramp and the pylon was too short to enable 

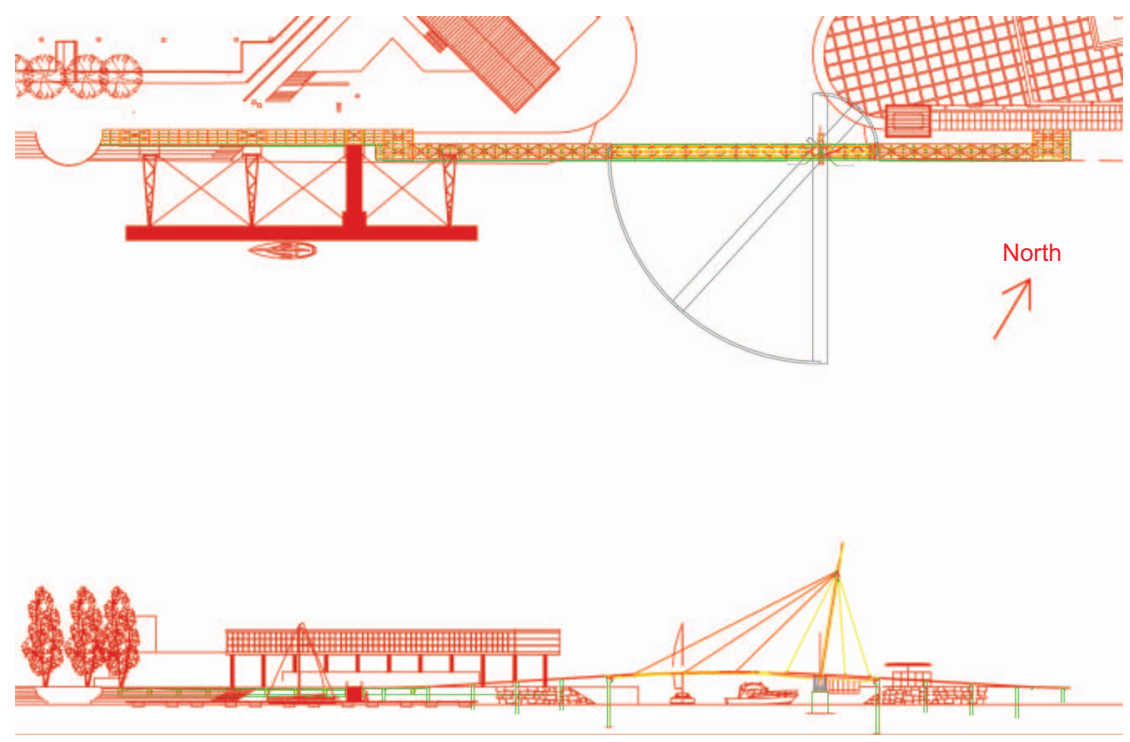

Figure 1. Overview of the general solution (source: unpublished 2005 document, Structural Project of Viana do Castelo Moveable Footbridge, by Lopes et al.)

the installation of a floating platform capable of supporting drilling equipment. The platform would also prevent boats from entering or exiting the marina. This was the first obstacle to overcome and the reason why the construction approach was changed. The new proposal of the contractor (Irmãos Cavaco SA, 2012) (Figure 6) consisted of the placing a steel tube, $2.70 \mathrm{~m}$ in diameter, that was specifically designed for this purpose and would also be used as the formwork. This proposal was well received by the design team, and a new structural solution using ten $40-\mathrm{mm}$ micropiles was selected. However, it was not possible to install a steel tube with a constant diameter.

The design team decided that the widest part of the steel tube, shown in Figure 6, with a height of $2.5 \mathrm{~m}$, should be placed on the riverbed, and a cavity $3.70 \mathrm{~m}$ in diameter by $2.5 \mathrm{~m}$ long

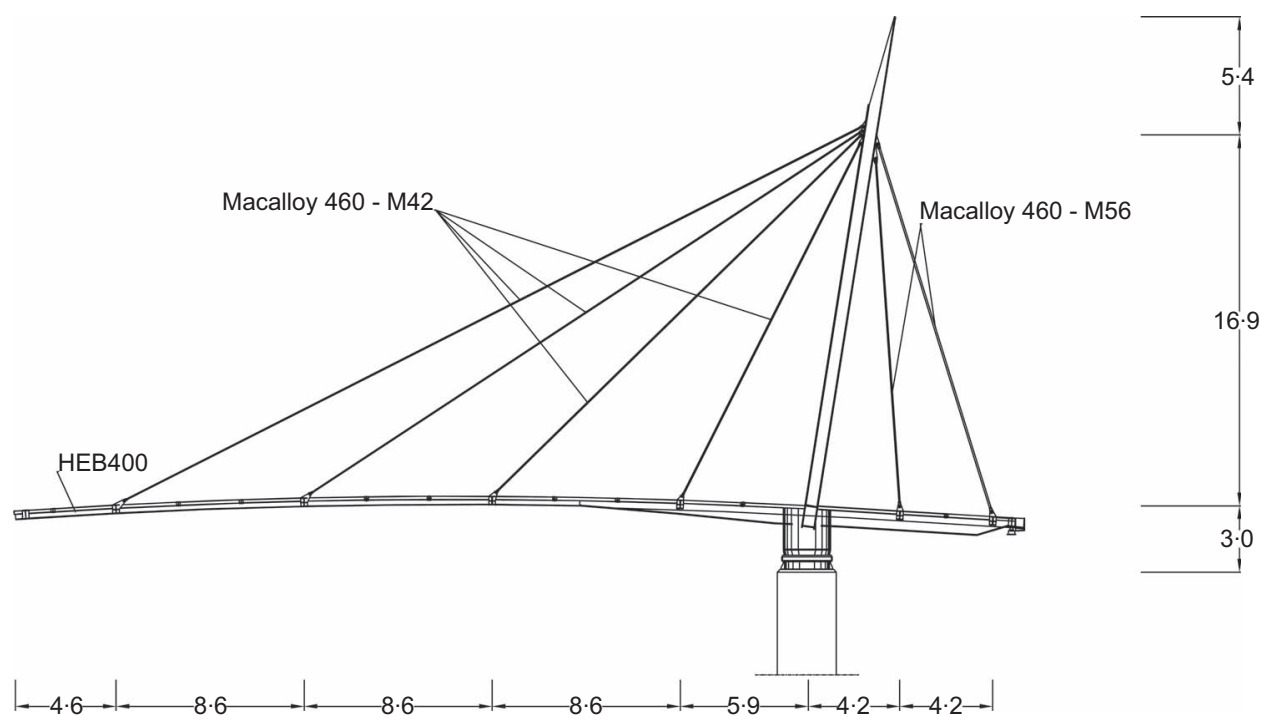

Figure 2. Elevation (dimensions in $\mathrm{m}$ ) 
Bridge Engineering

Volume 166 Issue BE4
The Viana footbridge:

construction and dynamic

monitoring

Barbosa, Magalhães, Caetano and

Cunha

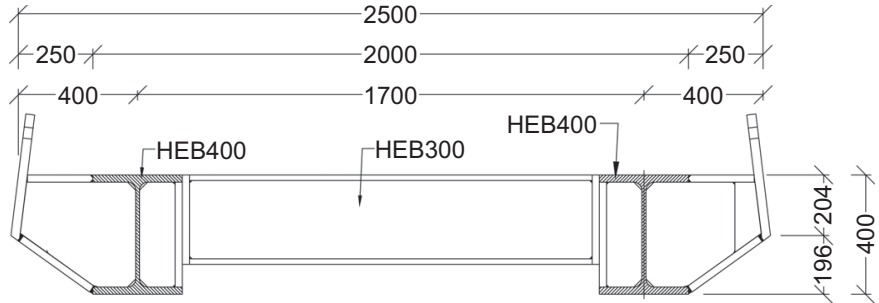

(a)

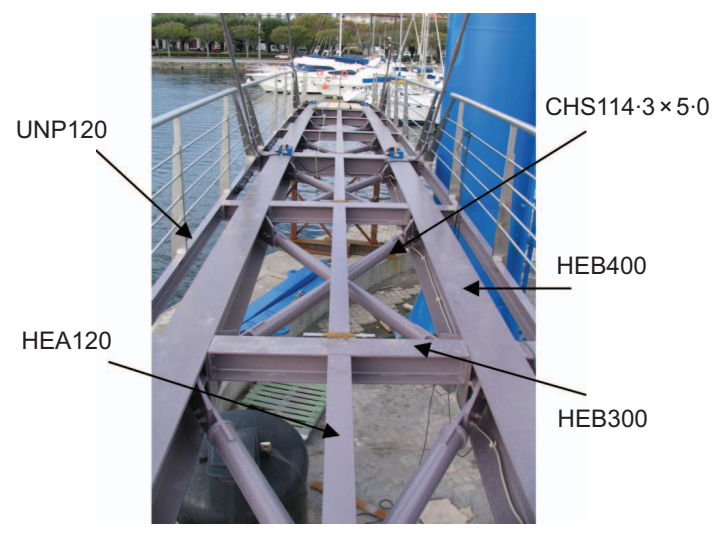

(b)

Figure 3. (a) Typical cross-section (dimensions in $\mathrm{mm}$ ); (b) detailed view of the deck

should be opened in its interior. The micropiles were then extended $13 \mathrm{~m}$ below this level. The contractor designed a steel formwork composed of three pieces: a sacrificial tube $3.70 \mathrm{~m}$ in diameter by $2.5 \mathrm{~m}$ long and two linkable parts for the tidal part of the pillar, each $2.70 \mathrm{~m}$ in diameter and $7 \mathrm{~m}$ long. The formwork was transported in pieces and assembled at the construction site (Figure 7). Simultaneously, the lower reinforcement including a set of tubes was prepared, as shown in Figure 8.

\subsection{Bridge structure}

The construction procedure adopted for the steel parts of the bridge was initially defined by considering transport limitations

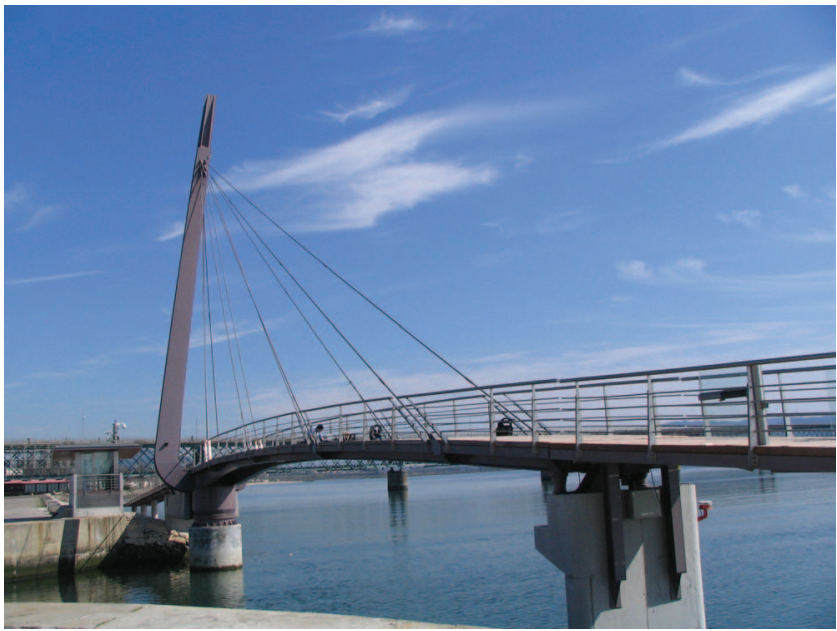

(a)

Figure 4. Images of the footbridge in the two operating positions: (a) closed, for use by pedestrians; and (b) open, to allow the entrance of sailing boats into the marina and site restrictions, namely, those imposed by the centenarian Eiffel Bridge serving the city of Viana do Castelo. This metallic railroad bridge linking Viana do Castelo to the south bank of the Lima River does not allow for the passage of transports over $3.90 \mathrm{~m}$ high. This limitation also constrained the choice of cranes. The passage of a $250 \mathrm{t}$ mobile crane was tested, demonstrating that this was the maximum crane capacity that could be used in the bridge construction.

The balance between the transport limitations and the minimisation of the welding joints led to the subdivision of the whole steel structure, as described in the next section, and the workshop fabrication was begun. Several details were

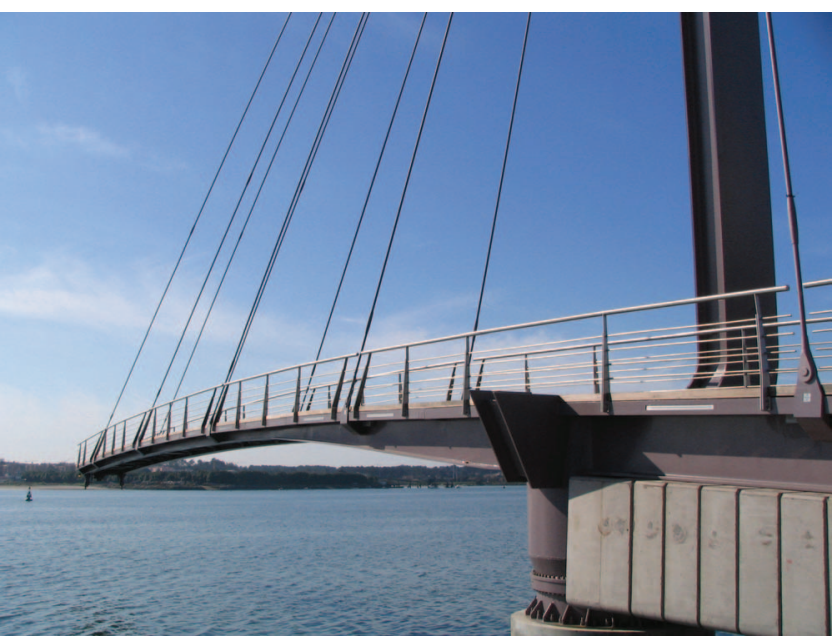

(b) 
The Viana footbridge:

construction and dynamic

monitoring

Barbosa, Magalhães, Caetano and

Cunha

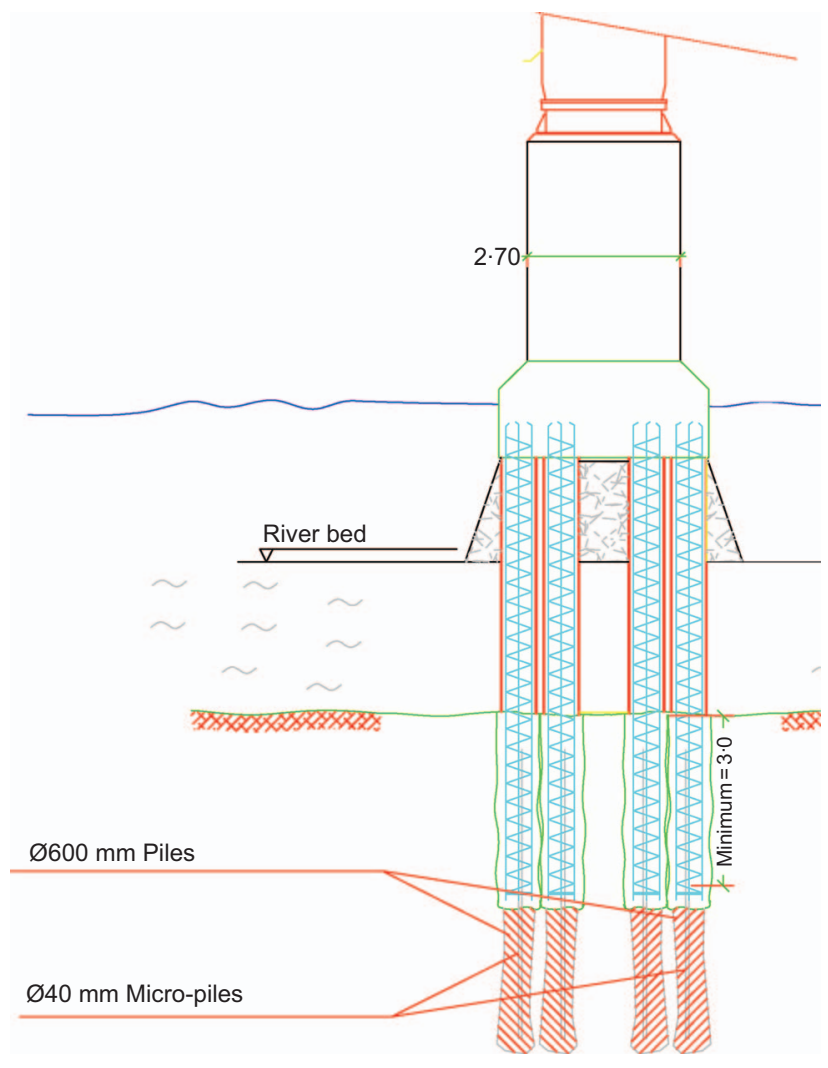

Figure 5. Initial solution (Delgado et al., 2008) (dimensions in m)

addressed during the fabrication, mainly related to the oilhydraulic system components. The stay-stressing plan was also finalised and approved.

\section{On-site construction and construction stages}

\subsection{Pivot pylon}

The pivot pylon steel formwork was topographically aligned and placed on the river bed, which had previously been dredged. On dry land, steel tubes were welded at the base of the formwork, and steel bars were fixed in the interior. Divers using pneumatic hammers drilled holes for the steel bars into the superficial granite layer, preventing the structure from moving in any direction. Cement and sandbags were positioned along the exterior perimeter to prevent the entrance of water at the bottom. In the following stage, a circular cavity, $3.70 \mathrm{~m}$ in diameter and $2.5 \mathrm{~m}$ high, was excavated in the formwork's interior using a trepan supported on a $100 \mathrm{t}$ crane. The water was pumped out, and cement was injected from the exterior wherever leaks were detected; finally, an epoxy-polyamide mastic, suitable for underwater use, was applied to the interior points of water entry.

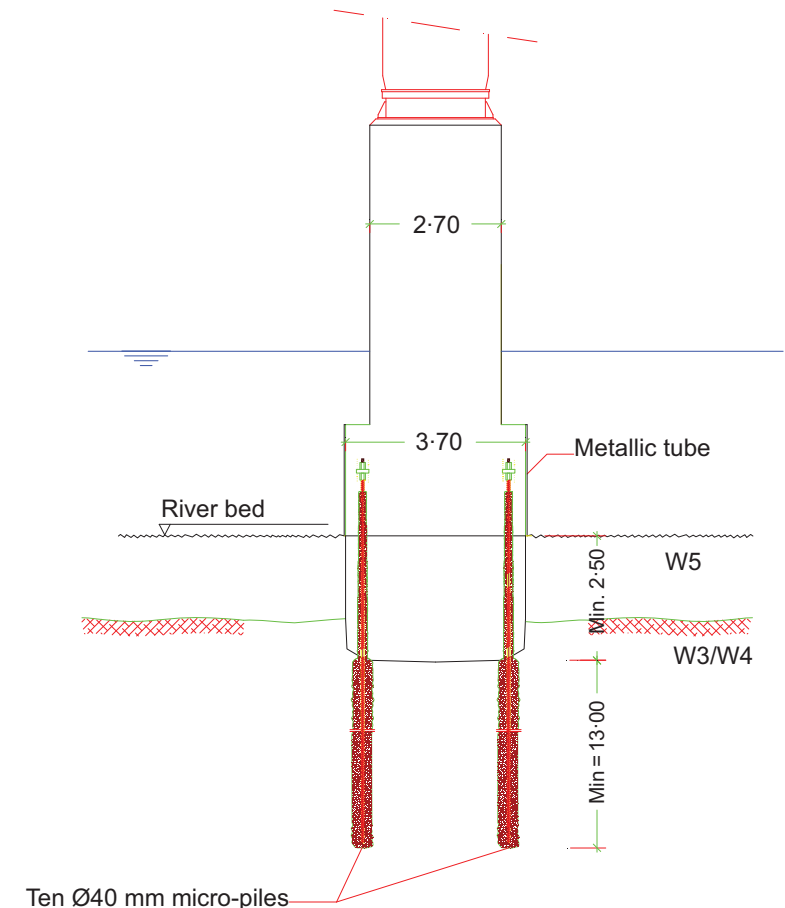

Figure 6. Contractor's solution (dimensions in m)

This cavity and the lower part of the formwork, also with the same diameter and height, were filled with the steel reinforcement structure, and 10 sacrificial steel tubes were positioned for the installation of the micropiles. These tubes were linked to plastic tubes on the formwork exterior to avoid the mixing of the injected cement with river water. Together, these components were lifted and placed on the upper part of the formwork.

In the first stage, concrete was filled into the first $4 \mathrm{~m}$; the micropiles were installed (Figure 9), and then the upper part of the formwork was dismantled into two separate pieces. The upper reinforcement steel, containing an inner steel tube to enable the future passage of the electrical cables and oilhydraulics pipes, was installed inside the upper formwork (Figure 10). In a subsequent phase, the whole formwork was filled with concrete, and threaded rods were placed at the top and welded to the reinforcement structure for the subsequent support of the mast.

\subsection{Ramp piers}

The ramp piers were built at the same time as the pivot pylon. All their foundations were executed with micropiles. For each circular pier $(0.50 \mathrm{~m}$ in diameter), a pair of micropiles $17 \mathrm{~m}$ long, consisting of bars $32 \mathrm{~mm}$ in diameter set at a $25^{\circ}$ inclination to vertical, were constructed on the existing slope, and the concrete foundations were made using commercial formworks. These concrete works were constrained by natural 
Bridge Engineering

Volume 166 Issue BE4
The Viana footbridge:

construction and dynamic

monitoring

Barbosa, Magalhães, Caetano and

Cunha

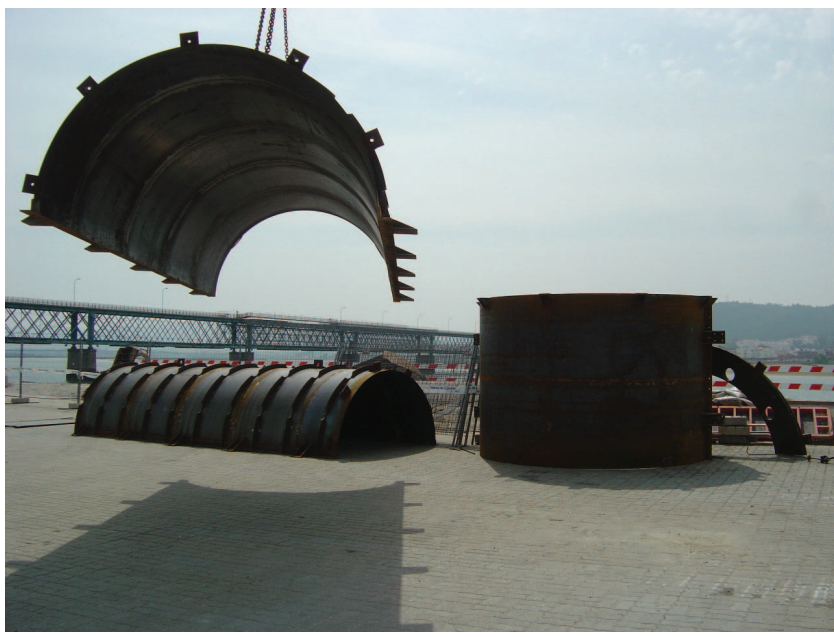

(a)

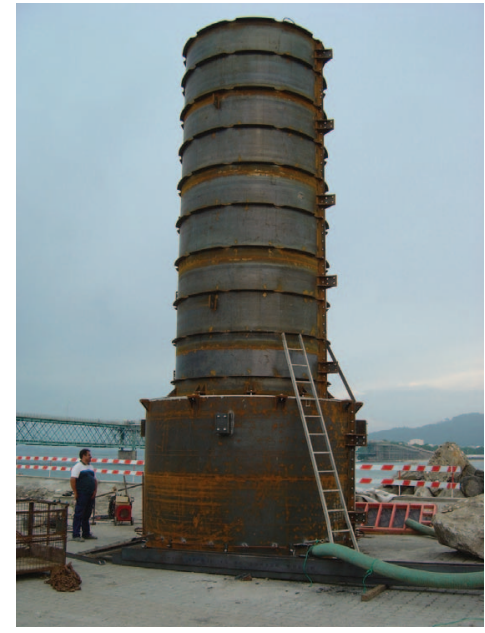

(b)

Figure 7. Formwork components and erected formwork

water flow due to tidal action. The closing pier on the counterweight side was built using the same process, but the foundations required eight micropiles, each $18 \mathrm{~m}$ long and $40 \mathrm{~mm}$ in diameter.

\subsection{Bridge structure}

Once the pivot pylon was ready and the ramp piers were near completion, the bridge structural steel components were delivered to the construction site over the quay. The bridge parts were placed in the following phases (Figure 11).

The first part was the steel cylinder; at the construction site, it was welded to the back span deck and parts of the main span segments. This piece was lifted, placed over the pivot pillar and bolted to the adjusting screws.

- The mast had to be transported in two separate pieces that were also welded at the quay. It was then lifted and placed in the existing openings in the cylinder. Four stays were previously tied at the mast top and later to the decks.

- At this point, the structure was manually rotated towards the quay, and the other part of the main span deck was welded. The main span deck was supported on a steel structure, with vertical adjustment positioned at the quay, and the remaining stays were placed using a crane.

- According to the stressing plan, the first six modules of the counterweight were inserted. Topographic readings revealed that the back span deck worked as a rigid group with the mast, and the main span deck displayed acceptable variations in position at its end.

- Once the counterweight was positioned, the supporting steel structure at the quay was removed, and the stays were tensioned to achieve the specified design stresses. Any

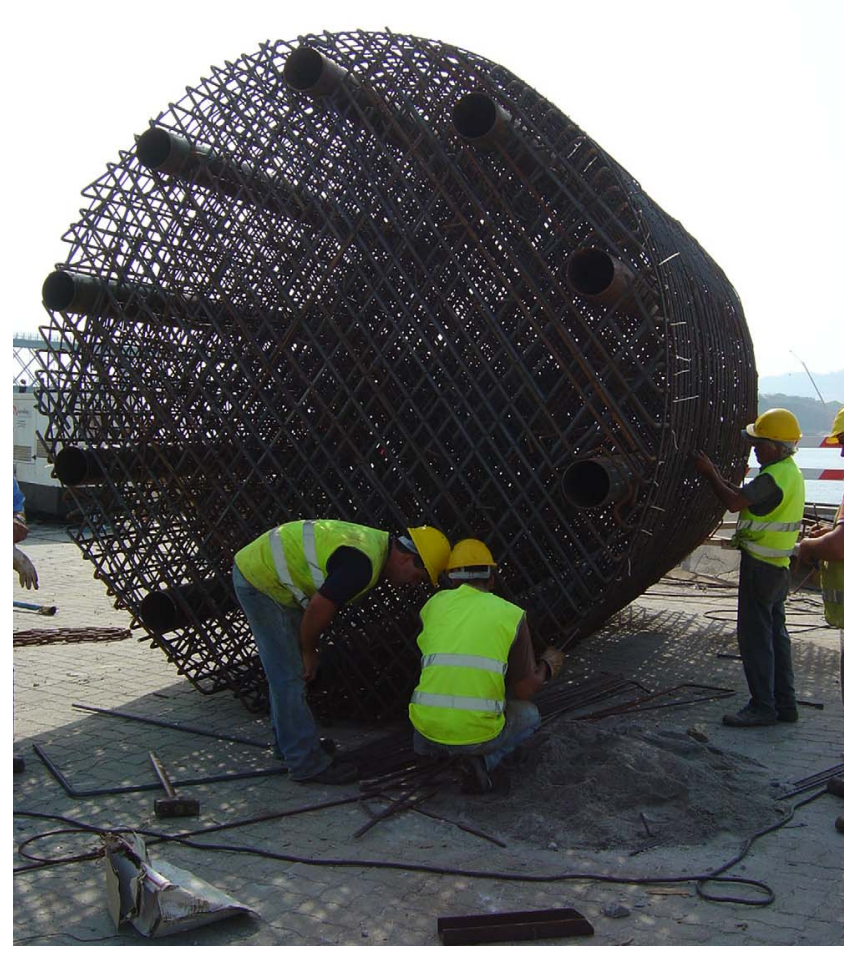

Figure 8. Lower reinforcement 
The Viana footbridge:

construction and dynamic

\section{monitoring}

Barbosa, Magalhães, Caetano and

Cunha

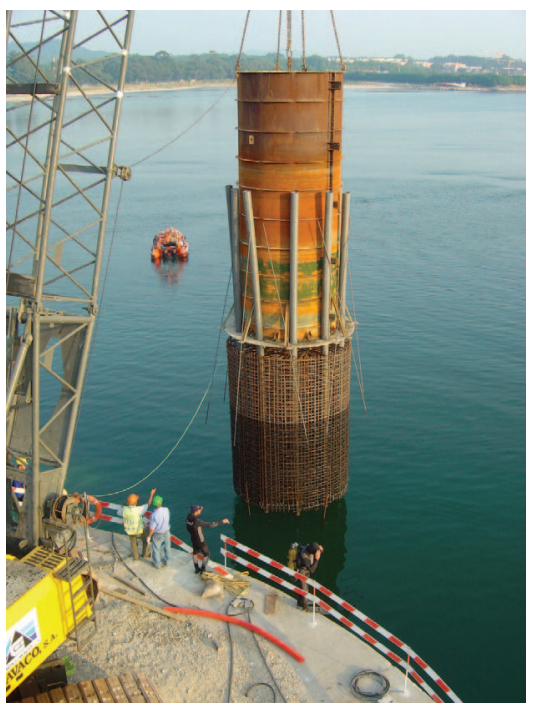

(a)

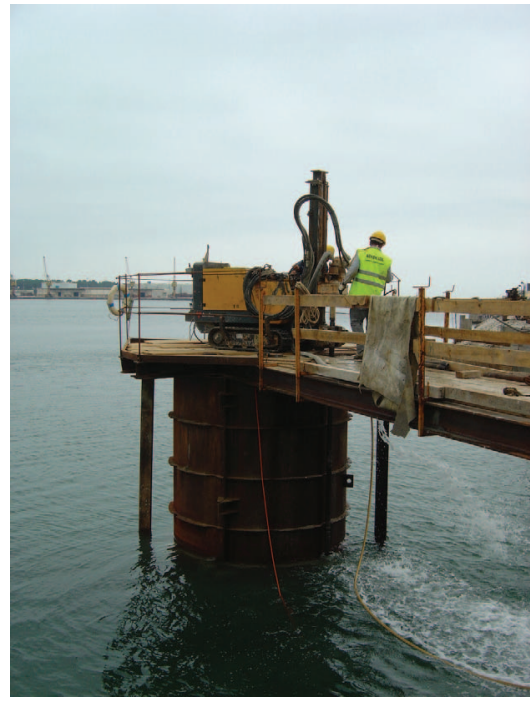

(b)

Figure 9. Placing of the lower reinforcing steel and installation of the micropiles

change of tension in a cable stay changed the forces in the other 10 stays. An iterative procedure was adopted to achieve the required balance between the design stresses and the topographic configuration of the deck. The risk of deformations due to tensioning, bending and twisting of the steel elements of the structure was thus minimised.

- The planetary gear units and electrical systems were installed in the cylinder, and the first mechanical rotations

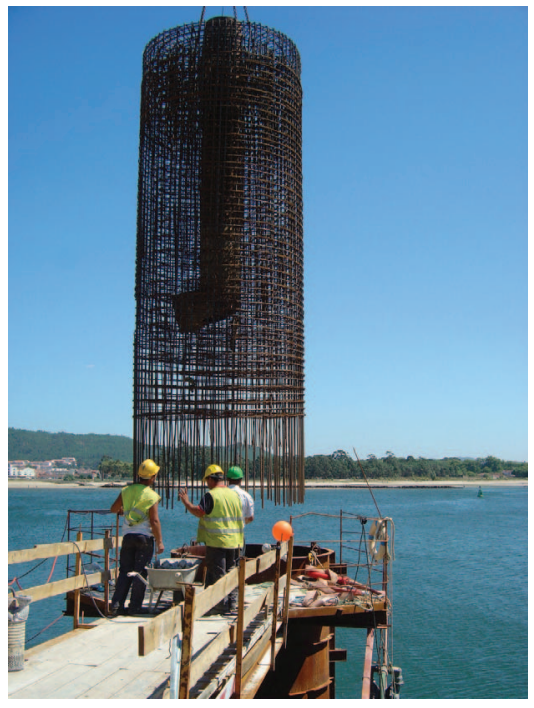

(a) were executed at very slow speed using a small hydraulic power pack with direct manual control.

- The structure was returned to its fixed position to execute additional work such as the installation of the electric and oil-hydraulics pipes, the wood surfacing and the handrails (in tubular $316 \mathrm{~L}$ stainless steel profiles).

In the final phase, the locking devices were installed and adjusted.

Figure 10. Placing of the upper reinforcing steel and view of the constructed pylon 
Bridge Engineering

Volume 166 Issue BE4
The Viana footbridge:

construction and dynamic

monitoring

Barbosa, Magalhães, Caetano and

Cunha

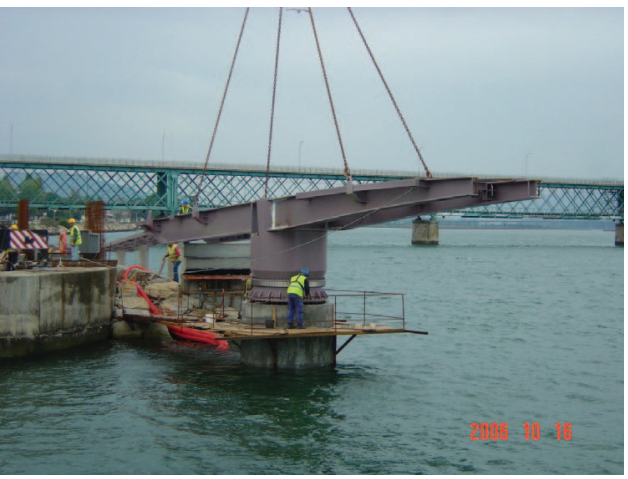

(a)

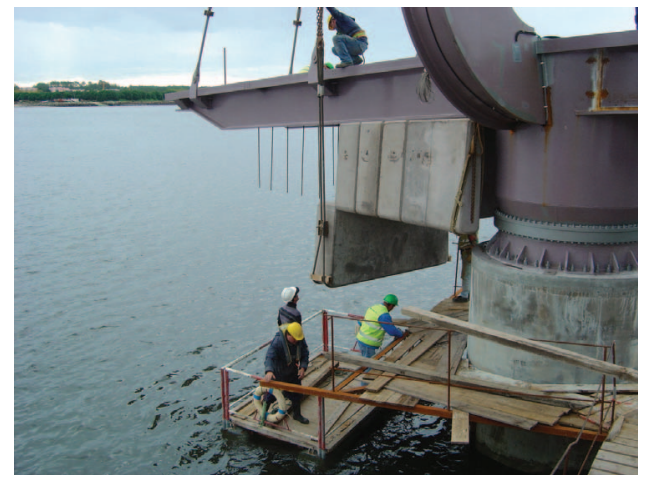

(d)

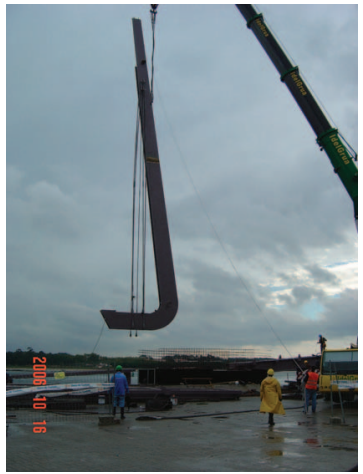

(b)

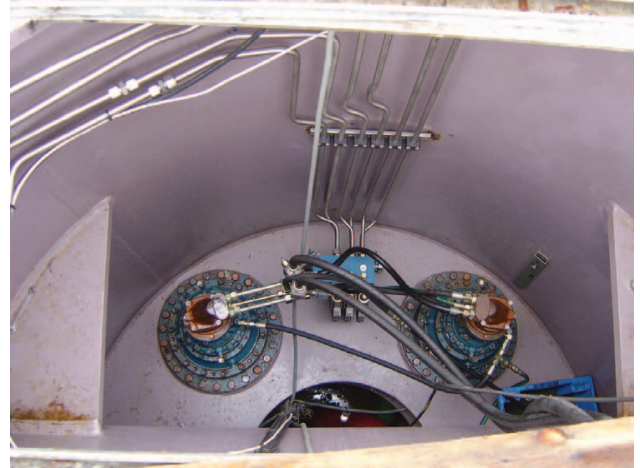

(e)

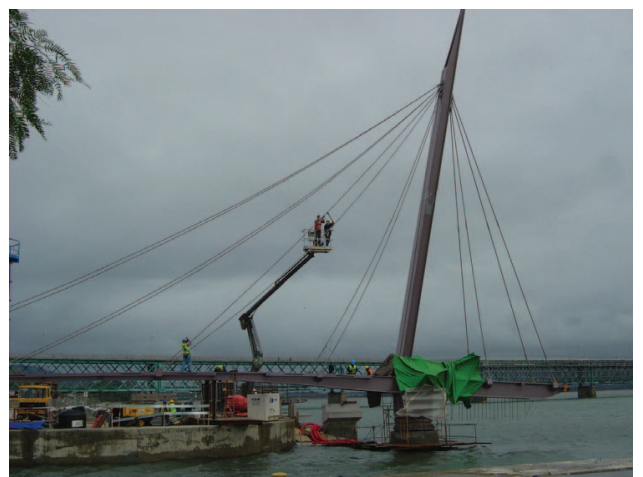

(c)

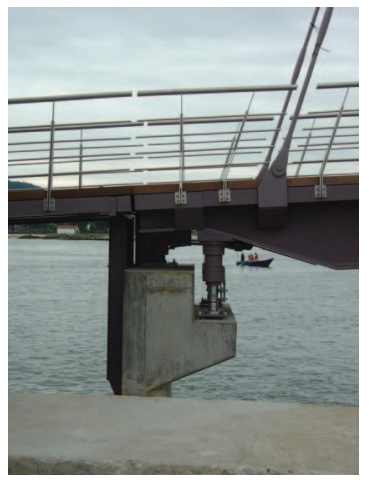

(f)

Figure 11. Phases of bridge construction: (a) installation of the first piece; (b) mast lifting and placement in the steel cylinder;

(c) installation of cable stays; (d) counterweight: modular insertion;

(e) planetary gear units; (f) locking devices

\subsection{Complementary works}

As main complementary works, the installation of all the electrical and video surveillance systems and the maritime signals, the final hydraulic operating system and the construction of the control building had to be outlined. When opening of the bridge is not allowed - for example, in winds above $70 \mathrm{~km} / \mathrm{h}$ (3-s gust), the arriving boats must wait; for this purpose, a $60-\mathrm{m}$ floating pontoon was installed in the Lima River (Figure 12). This pontoon, composed of five individual floating pontoons each $12 \mathrm{~m}$ long, was fixed to concrete blocks executed in the west quay ramp.

The electrical works consisted of placing cables along the decks inside plastic pipes supported above the wood surfacing, the installation of illumination and sound warning rotation signals. Two gates and semaphores were installed at the access platforms to restrict bridge traffic when the bridge is opening or open. Before the opening manoeuvre, when the locking devices are being disarmed, the management software induces electrical signals that simultaneously activate the sound warning rotation signal, the red light at the semaphores and the closing of the

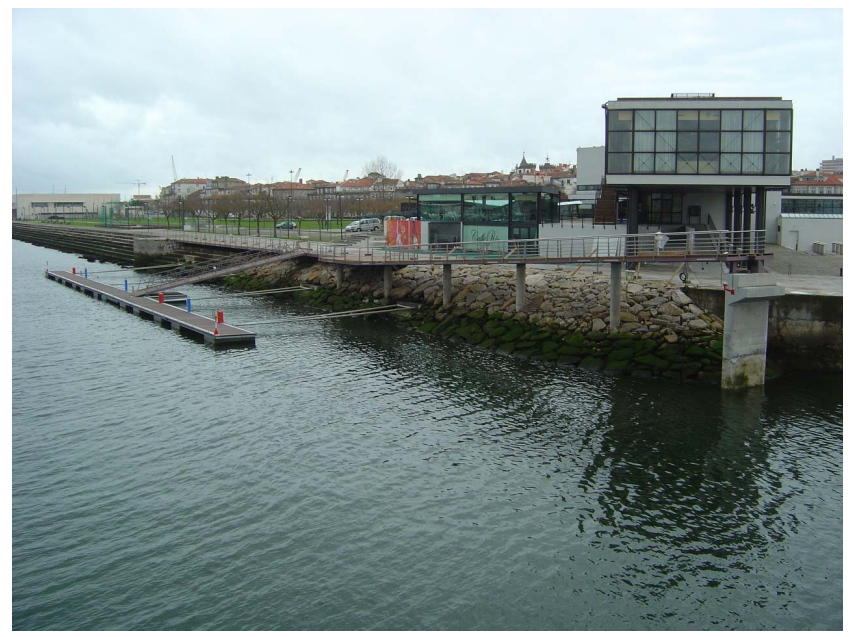

Figure 12. Waiting pontoon and west access platform 
The Viana footbridge:

construction and dynamic

monitoring

Barbosa, Magalhães, Caetano and

Cunha

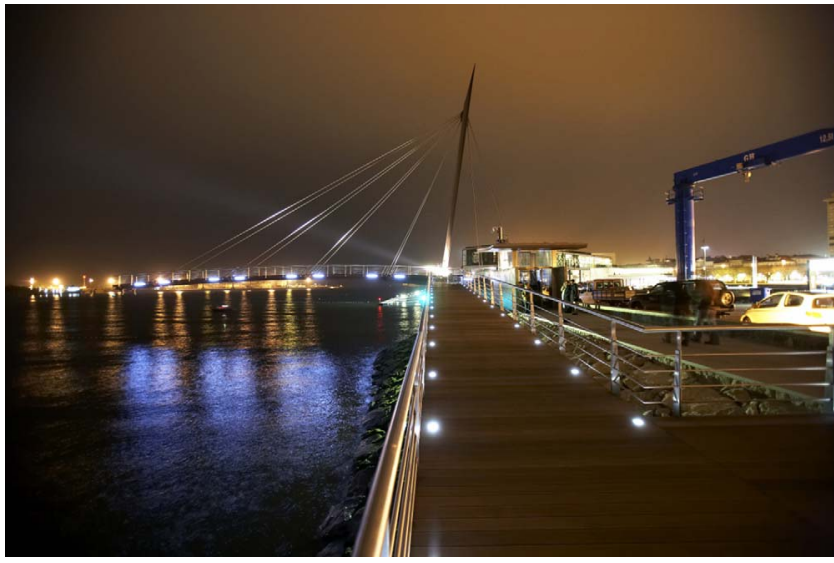

Figure 13. Night-time photograph: illumination and navigational lights

automatic gates. When the bridge is closing the reverse process is executed. Navigation lights were also installed at the closing piers and over the posterior deck (Figure 13). Communication between the switchboard in the control building and the switchboard from the west side is by radio.

The system command is performed totally at the control building (Figure 14), where the hydraulic power pack (Figure 15), the switchboards and the surveillance equipment are located. The power pack includes a main variable displacement axial piston pump with electronic proportional control for the main movement, an emergency variable displacement axial piston pump with electronic proportional control and an auxiliary gear pump for all remaining actuators and control and safety valves. All system commands and equipments status, including peripheral devices, are housed in an electronic cabinet that includes a 17 -in $(43-\mathrm{cm})$ touch-screen control panel (Figure 15). This control panel has a graphical summary representation of the bridge, and the operator must confirm, step by step, a pre-programmed sequence that provides total safety for the people and equipment during opening and closing manoeuvres.

\section{Bridge behaviour: verifications, static and dynamic monitoring}

The verification of the global bridge behaviour was performed during the last phases of construction. The oil-hydraulics system was tested and optimised in order to reach a total time of approximately $1 \mathrm{~min}$ during each rotation manoeuvre and the locking systems were adjusted to reduce undesirable efforts in the steel pieces.

Static and dynamic monitoring activities were developed by the laboratories LABEST (2012) and VIBEST (2012) from the Faculty of Engineering, University of Porto (FEUP), respectively.

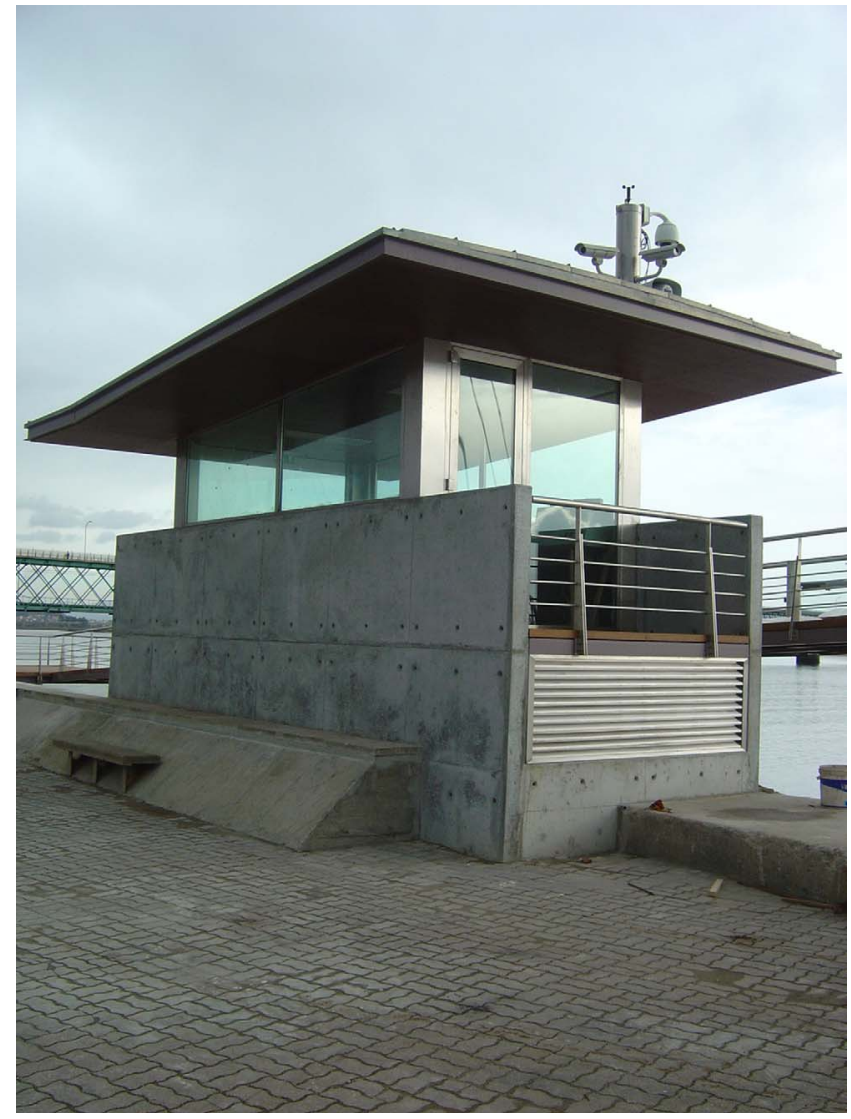

Figure 14. Control building

The installation of monitoring systems (Figure 16) began at an early stage, when the structure was dismantled over the quay, continued during the assembling of the bridge and ended 4 months after opening to the public.

These monitoring activities, as well as commissioning tests performed after construction and before the opening ceremony, were required by the bridge owner, as is usual in Portugal for similar cases.

In particular, the light and lively nature of the footbridge under pedestrian excitation justified the performance of a set of dynamic tests (Cunha and Caetano, 2006; Cunha et al., 2007) by VIBEST/FEUP at the request of the construction company. These included two ambient vibration tests, the measurement of stay cable forces using the vibration method, tests with groups of pedestrians to evaluate the level of the bridge vibration and the monitoring of the bridge accelerations during 4 months.

The following sections describe the performed tests (Figure 17), the procedures used for the identification of the bridge modal properties and for the estimation of stay cable forces, the 
Bridge Engineering

Volume 166 Issue BE4
The Viana footbridge:

construction and dynamic

monitoring

Barbosa, Magalhães, Caetano and

Cunha

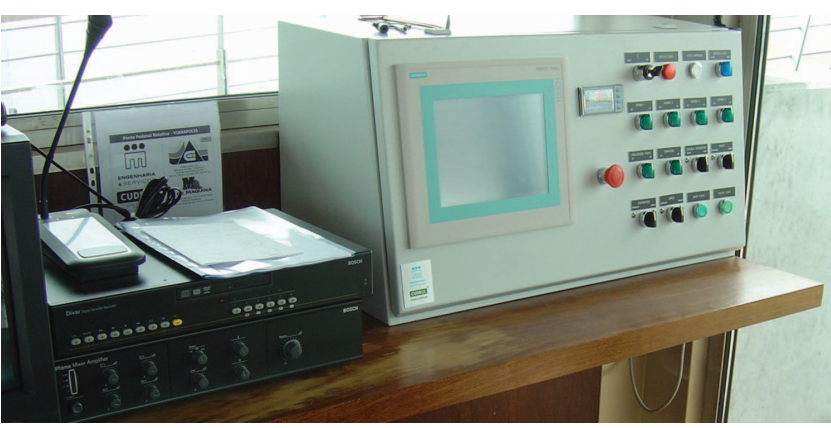

(a)

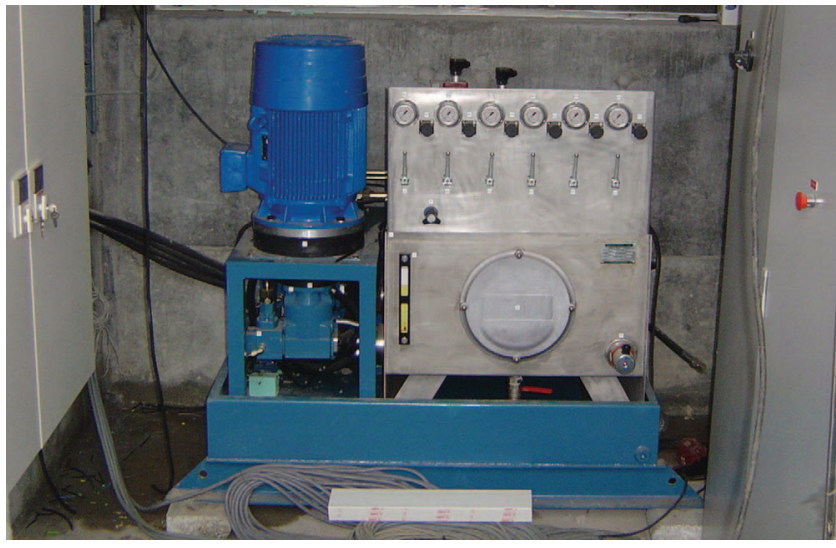

(b)

Figure 15. Touch-screen control panel (a) and hydraulic power pack (b)

acceleration levels observed during the pedestrian tests and the outputs of the dynamic monitoring programme.

\subsection{Ambient vibration tests}

The goal of the ambient vibration tests was the identification of the bridge modal parameters, namely natural frequencies and mode shapes, for the two alternative structural scenarios: open and closed bridge. These dynamic parameters are an important basis for the validation and eventually update of the numerical models developed by the bridge designer. They were also important for the definition of the critical step frequencies to be used in the tests with groups of pedestrians.

The first ambient vibration test was performed with the bridge in the cantilever position during construction, before installation of the timber surfacing. Figure 18 shows a detail of the placement of the measuring equipment at that stage.

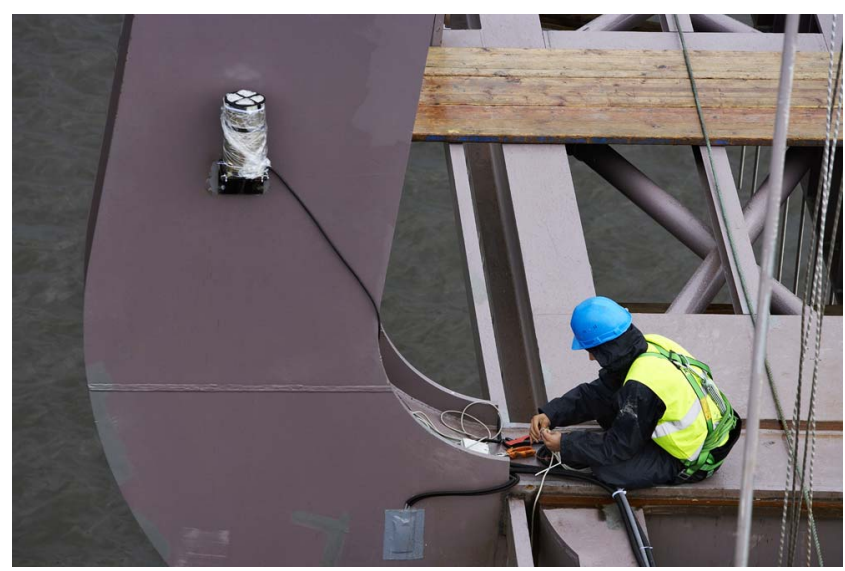

Figure 16. Installation of monitoring equipment
The second ambient vibration test was performed after construction in the closed position, corresponding to the structural system that is used when the footbridge is crossed by pedestrians.

The bridge response to the ambient excitation was measured using four seismographs with tri-axial force-balance accelerometers and analogue to digital converters of 18 bits (Figure 18 shows two units). The sections instrumented in both tests are marked in Figure 19. The nine selected sections were covered in eight setups, using a reference section to link the results of each setup. In each section, measurements were performed in both sides of the deck (over the two main longitudinal beams) in order to provide data for the identification of torsion modes.

The modal parameters were identified based on the peak picking method. The estimation of the natural frequencies was

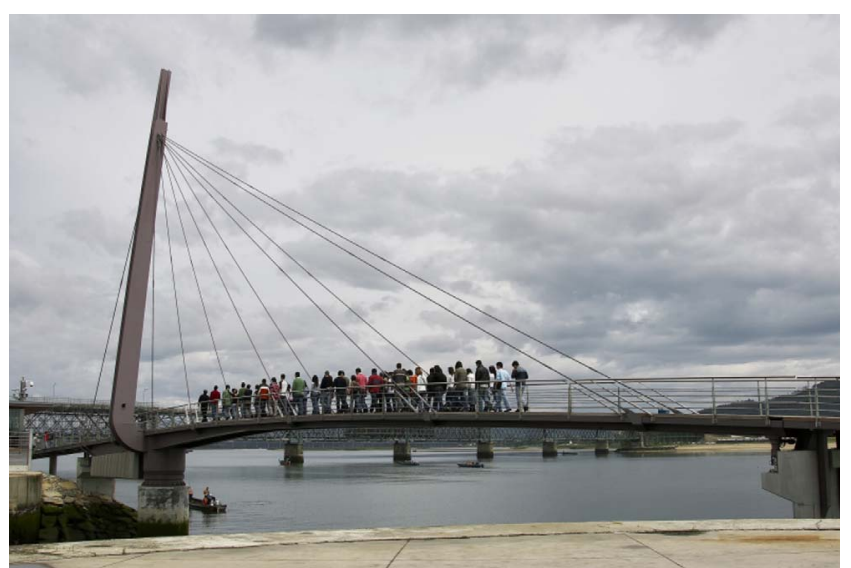

Figure 17. Dynamic test 
The Viana footbridge:

construction and dynamic

monitoring

Barbosa, Magalhães, Caetano and

Cunha

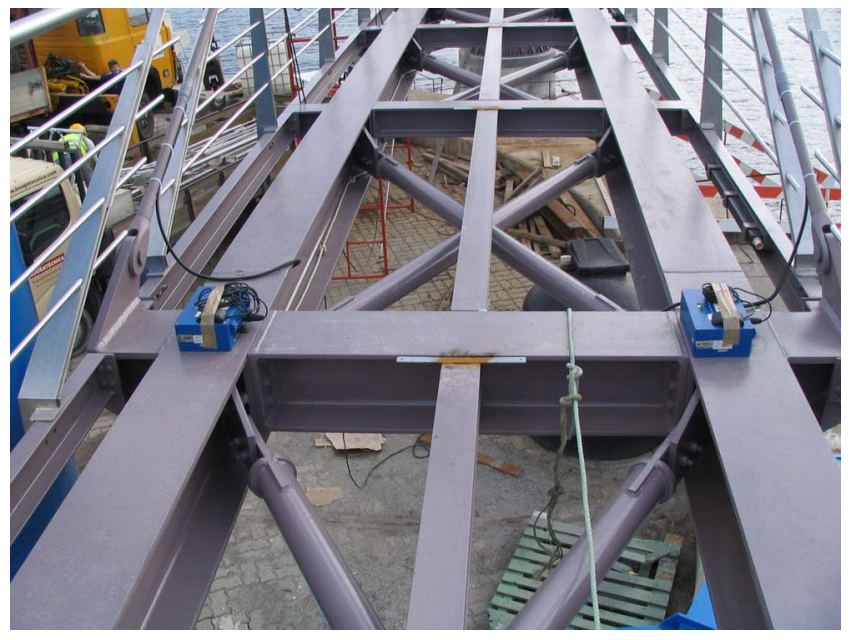

Figure 18. Bridge deck during the first ambient vibration test and two measuring units

based on the average normalised power spectrum density functions associated with the vertical and lateral accelerations. Mode shapes were identified from the transmissibility functions relating the measured ambient vibration responses at each instrumented section with the simultaneous response at the reference section.

The average normalised power spectrum density functions of the vertical accelerations collected in both ambient vibration tests are represented in Figure 20. It can be observed that these graphics exhibit not only the peaks that are associated with the global modes of the deck but also peaks that represent local modes of the stay cables or combined modes of the deck and stay cables (Caetano et al., 2000a, 2000b). This fact originates an increased difficulty in the identification of global modes whenever the corresponding natural frequency is close to a cable harmonic. Such is the case of the second vertical mode associated with the open position, for which it was not possible to define an exact value for the natural frequency, as several peaks around $3.6 \mathrm{~Hz}$ with the same mode shape were identified. The most relevant mode shapes are plotted in Figures 21 and 22.

\subsection{Measurement of stay cable forces}

In some phases of the construction process, the axial forces installed in the stay cables were estimated based on the measured frequencies.

The measurements were performed under ambient excitation, using a piezoelectric accelerometer conveniently fixed to the stay cables. Acceleration time records were collected and processed by means of a portable Fourier analyser installed in a laptop. Examples of the resulting average auto-spectra density functions are shown in Figure 23.

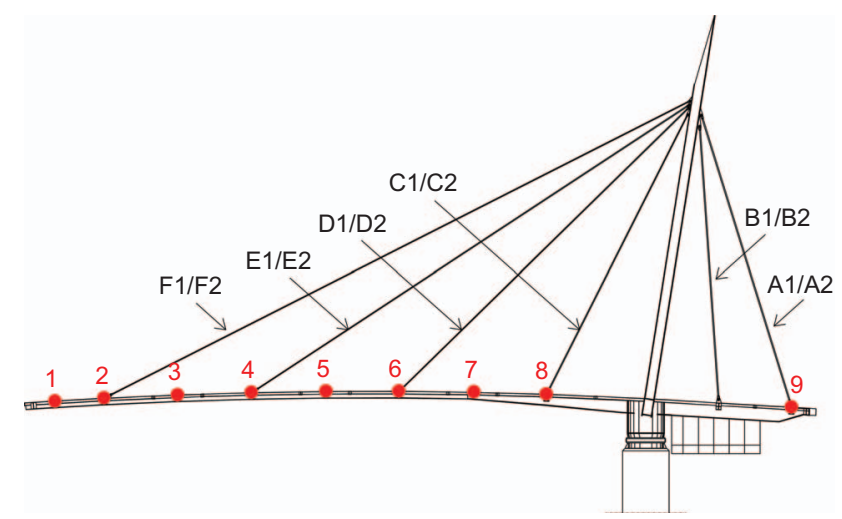

Figure 19. Instrumented sections

The plot of the successive stay cable frequencies compared with the corresponding mode number represented in Figure 24 shows that for all stay cables except the two longest backstays A1 and A2 (see Figure 19) significant deviations from the straight line expected for a tensioned cable occur. This fact results from the low tension installed in those cables (with stresses varying from 20 to $130 \mathrm{MPa}$ ), and invalidates the application of the vibrating chord theory relating the installed tension to the measured natural frequency of the cable. For that reason, the estimation of stay cable forces was based on a combination of the results from a numerical modelling of the cables with the recorded frequencies.

Each cable was individually discretised into 20 beam elements, the corresponding bending and axial stiffness defined by the properties of the cable full cross-section. An initial strain was introduced to simulate the expected installed tension and the permanent loads (cable weight) were applied. From a geometric non-linear analysis, the deformed configuration of the cable was determined, and the tangent stiffness matrix was constructed. This matrix was subsequently used in the evaluation of natural frequencies of the stay cable. These frequencies were compared with the measured frequencies and an iterative updating of the initial strain in the cable was done until a good match between the experimental and numerical natural frequencies was achieved. Figure 24 presents the numerically estimated forces for one of the construction phases (open position, before installation of the timber surfacing).

These measurements also permitted the detection of a significant and unexpected difference of cable forces between two identical cables (B1 and B2), which was subsequently corrected with a final re-tensioning of the cable stays.

\subsection{Tests with groups of pedestrians}

In order to assess the comfort level associated with human induced loads, dynamic tests were conducted with groups of 


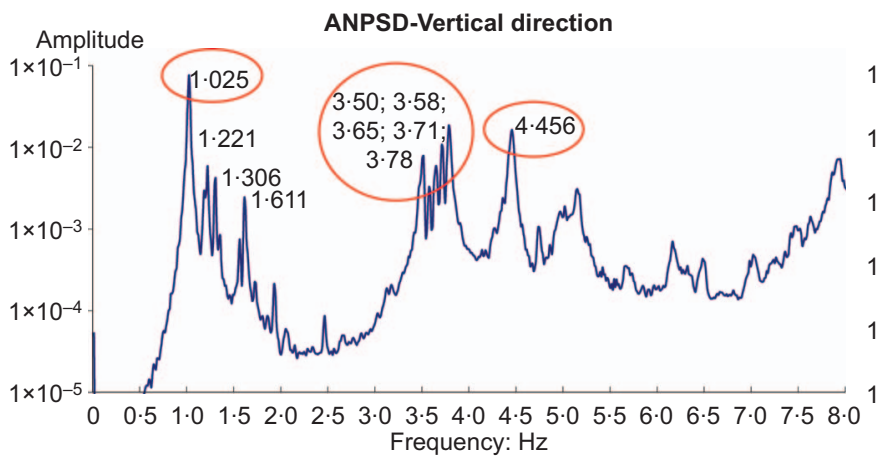

(a)

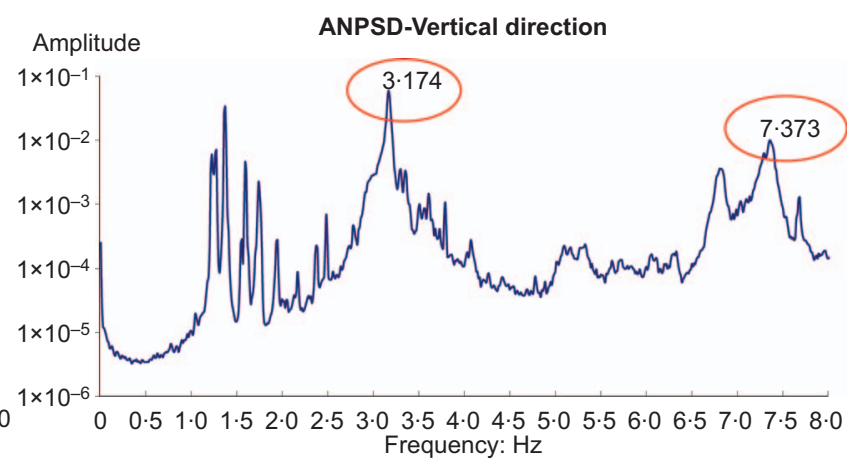

(b)

Figure 20. Average normalised power spectrum density functions of the vertical acceleration for the two bridge positions: (a) bridge open; (b) bridge closed

\section{$f=1.03 \mathrm{~Hz}$}

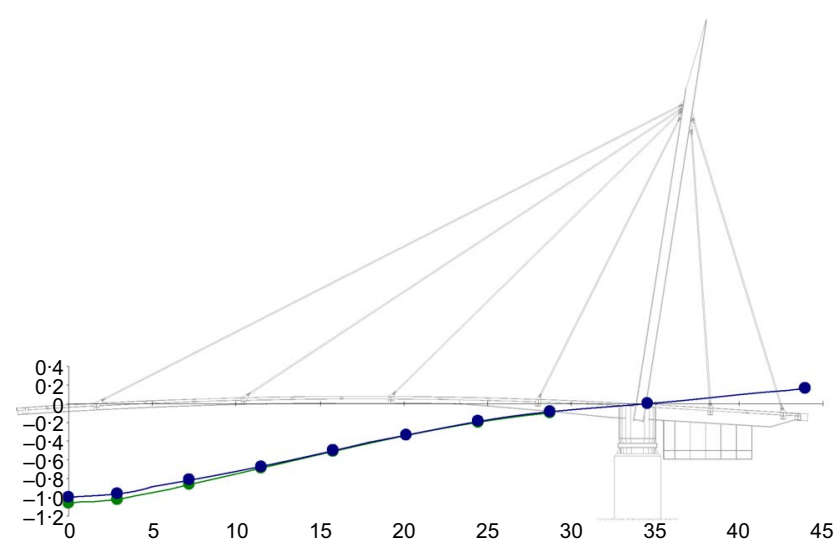

$f=4.46 \mathrm{~Hz}$

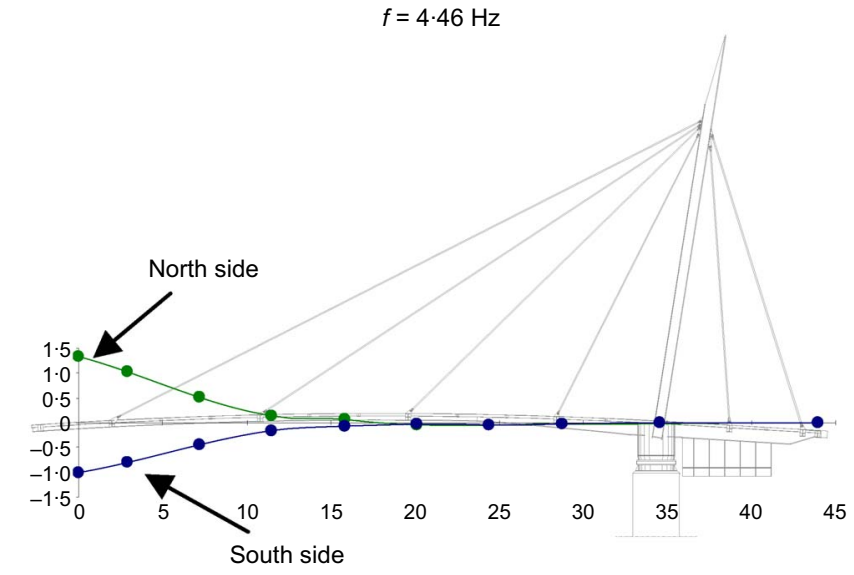

Figure 21. Bridge in open position: first two vertical mode shapes $(1 \cdot 03,3.50-3.78 \mathrm{~Hz})$, first torsion mode shape $(4.46 \mathrm{~Hz})$ and first lateral mode shape $(0 \cdot 98-1 \cdot 04 \mathrm{~Hz})$
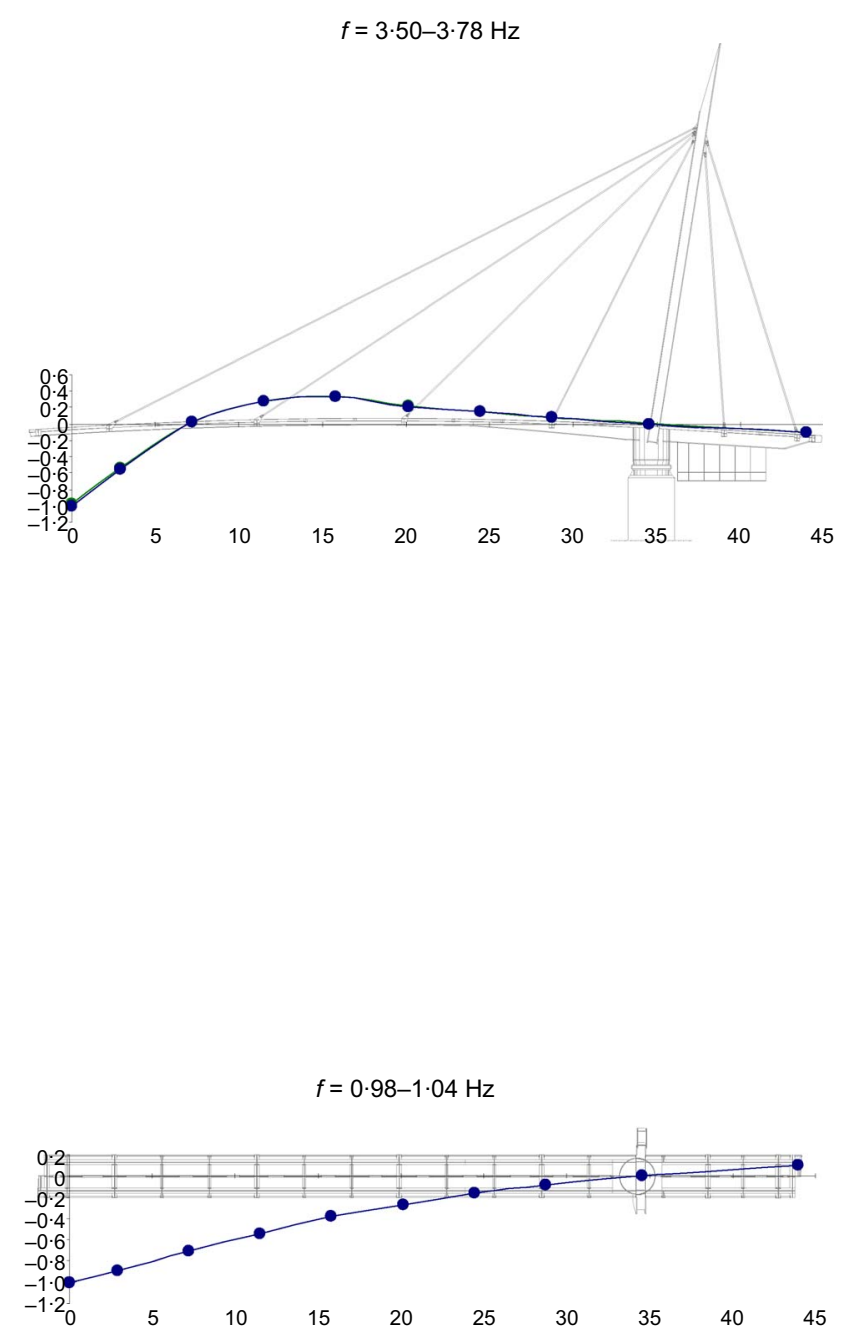
The Viana footbridge:

construction and dynamic

monitoring

Barbosa, Magalhães, Caetano and

Cunha

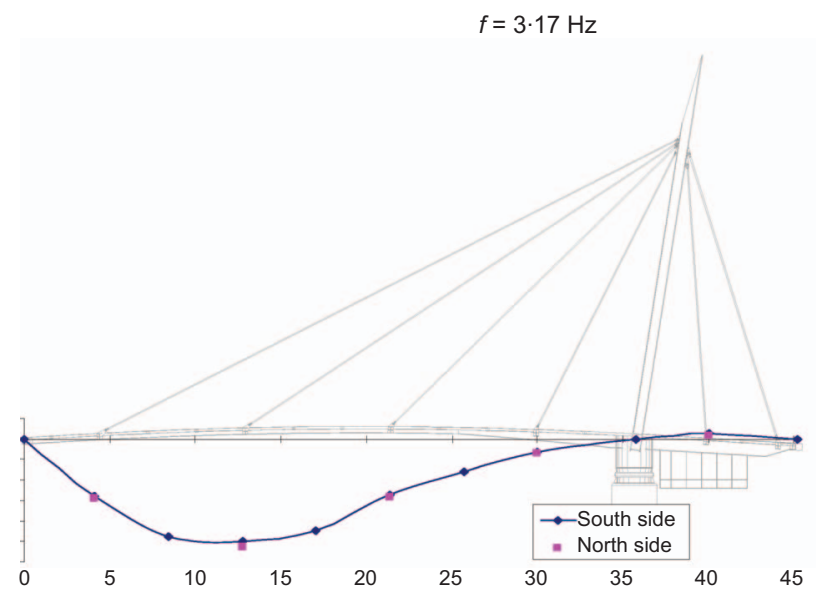

$f=4 \cdot 09 \mathrm{~Hz}$

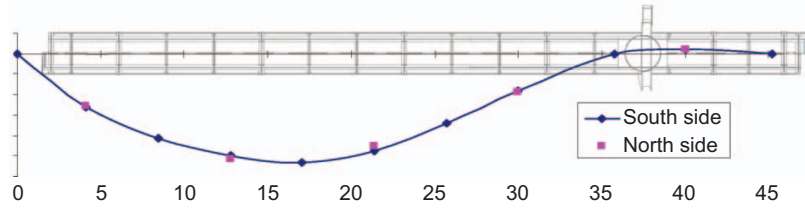

$f=7 \cdot 37 \mathrm{~Hz}$

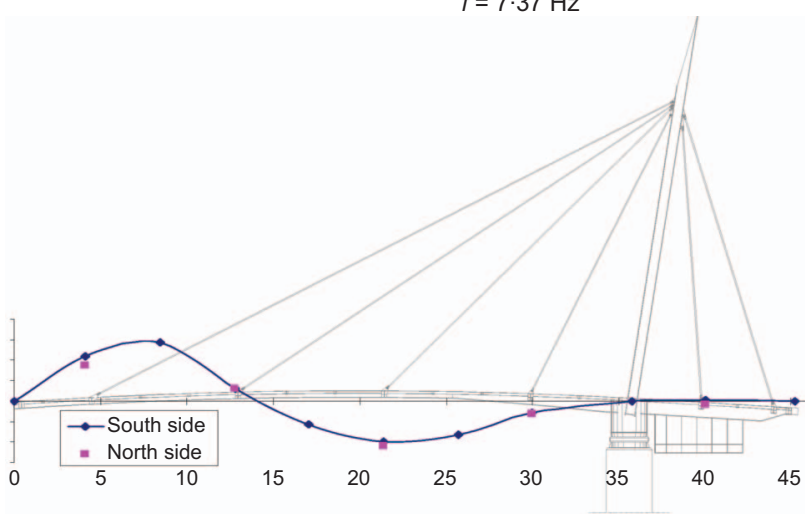

$f=6 \cdot 82 \mathrm{~Hz}$

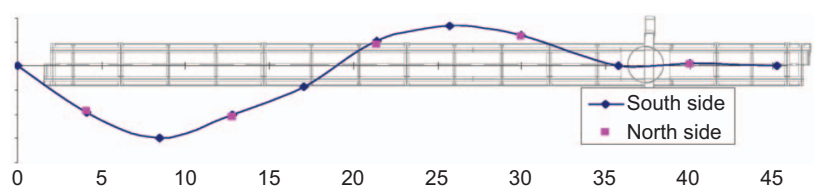

Figure 22. Bridge in closed position: first two vertical $(3 \cdot 147$,

$7 \cdot 37 \mathrm{~Hz})$ and lateral mode shapes $(4 \cdot 09,6 \cdot 82 \mathrm{~Hz})$

pedestrians for a set of load scenarios taken as critical by analysis of the bridge frequencies: running in different group sizes, trying to induce resonance in the first vertical mode; jumping in small groups, or direct excitation of the stay cables close to anchorage, to reproduce the actions induced by vandals; walking in a stream, trying to induce resonance in the

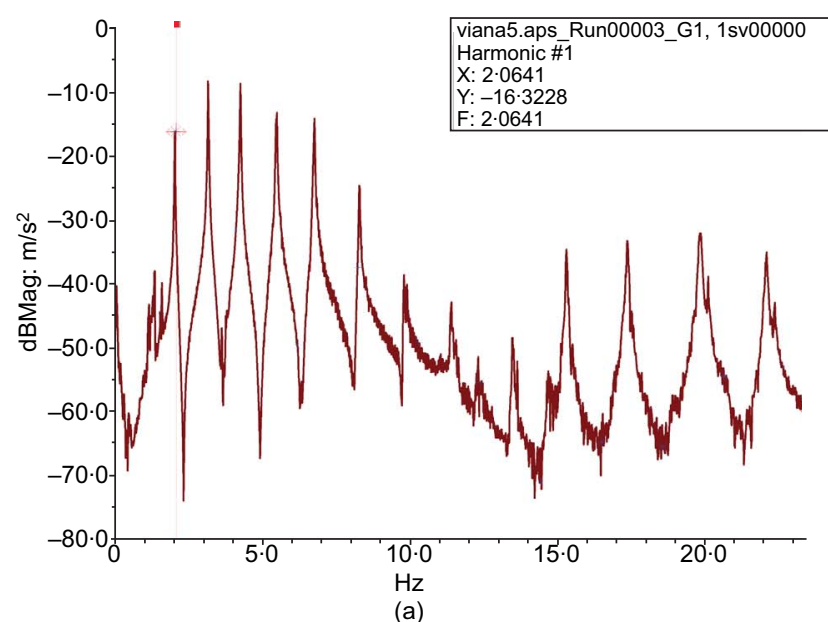

Figure 23. Auto-spectra density functions measured in two stay cables: (a) stay cable in central span; (b) backstay cable first mode by means of the second harmonic of the vertical load, or else trying to induce resonant vibrations in stay cables for the possible detection of parametric vibrations. Figure 25 shows images of the tests. Table 1 systematises the maximum measured acceleration associated with the various scenarios. It is relevant to mention that a metronome was used in order to

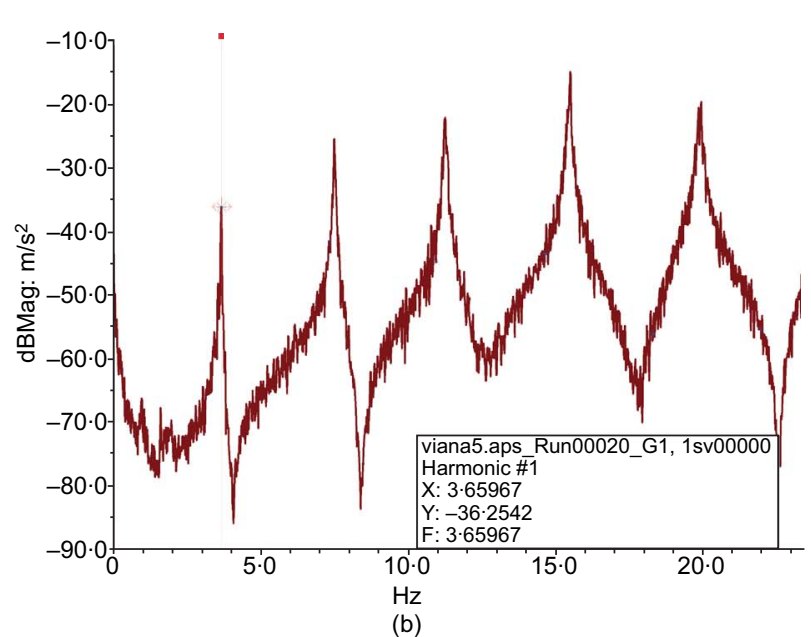


Bridge Engineering

Volume 166 Issue BE4
The Viana footbridge:

construction and dynamic

monitoring

Barbosa, Magalhães, Caetano and

Cunha

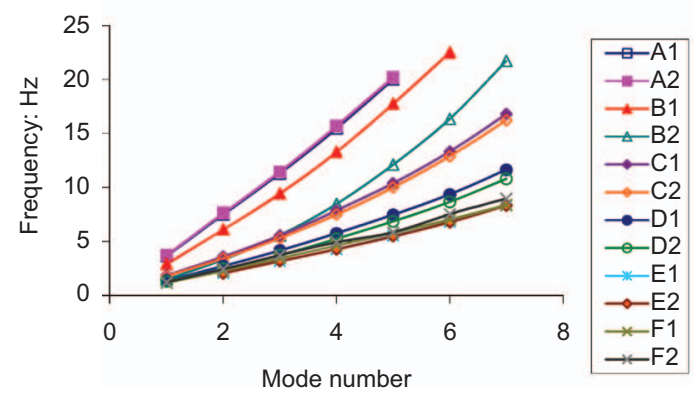

\begin{tabular}{ccc}
\hline Stay cable & Length: $\mathrm{m}$ & Force: $\mathrm{kN}$ \\
\hline A1 & $17 \cdot 5$ & $262 \cdot 3$ \\
A2 & $17 \cdot 5$ & $270 \cdot 8$ \\
B1 & $15 \cdot 9$ & $143 \cdot 3$ \\
B2 & $15 \cdot 9$ & $41 \cdot 8$ \\
C1 & $18 \cdot 0$ & $35 \cdot 9$ \\
C2 & $18 \cdot 0$ & $32 \cdot 3$ \\
D1 & $23 \cdot 4$ & $34 \cdot 7$ \\
D2 & $23 \cdot 4$ & 28.0 \\
E1 & $30 \cdot 2$ & $34 \cdot 4$ \\
E2 & $30 \cdot 2$ & 33.8 \\
F1 & 37.9 & $66 \cdot 7$ \\
F2 & 37.9 & 74.7 \\
\hline
\end{tabular}

Figure 24. Measured stay cable frequencies and identified forces in the open position, before installation of timber surfacing

help the pedestrians synchronise. However, this synchronisation is not achieved with large groups or streams of untrained pedestrians.

The results presented in Table 1 show that the footbridge exhibits a satisfactory behaviour when crossed by streams of pedestrians walking with step frequencies equal to the natural frequencies of the stay cables or to half the fundamental vertical frequency. Vibration levels of acceleration of $0 \cdot 3$ $0.7 \mathrm{~m} / \mathrm{s}^{2}$ have been recorded, which are well within the medium comfort range defined by the human-induced vibration of steel structures guidelines (HIVOSS, 2007). The running scenario, however, leads to significant vibrations. When the bridge is crossed by a single pedestrian running in the critical frequency, a maximum acceleration of $1.5 \mathrm{~m} / \mathrm{s}^{2}$ was recorded. This value is already close to the intolerable limit defined in Bachmann et al. (1995). Small groups of 10 pedestrians running synchronously or larger groups (30 persons) running freely motivated acceleration levels of approximately $4 \mathrm{~m} / \mathrm{s}^{2}$, which are undesirable from the point of view of fatigue of nonstructural elements. It should be noticed that these high amplitude events have a very short duration in the case of small groups, considering the small length of the bridge. This can be observed in Figure 26 for the time series recorded in the twoway crossing of the footbridge by 10 pedestrians running with a step frequency of $3 \cdot 1 \mathrm{~Hz}$. Streams of running pedestrians (in

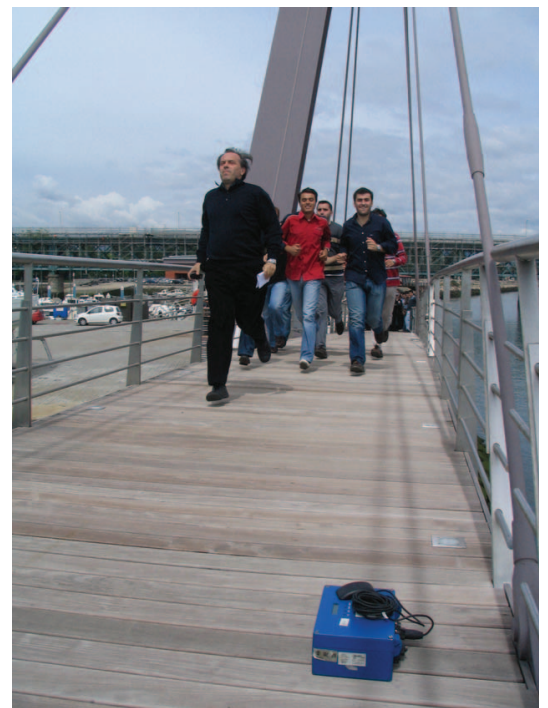

(a)

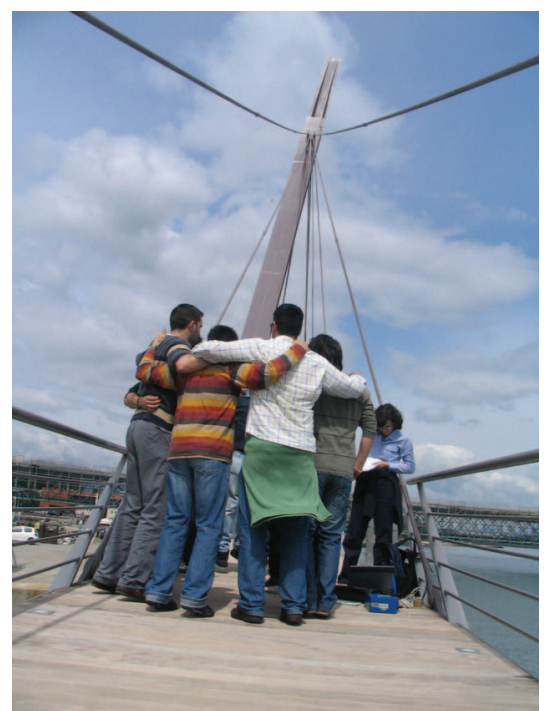

(b)

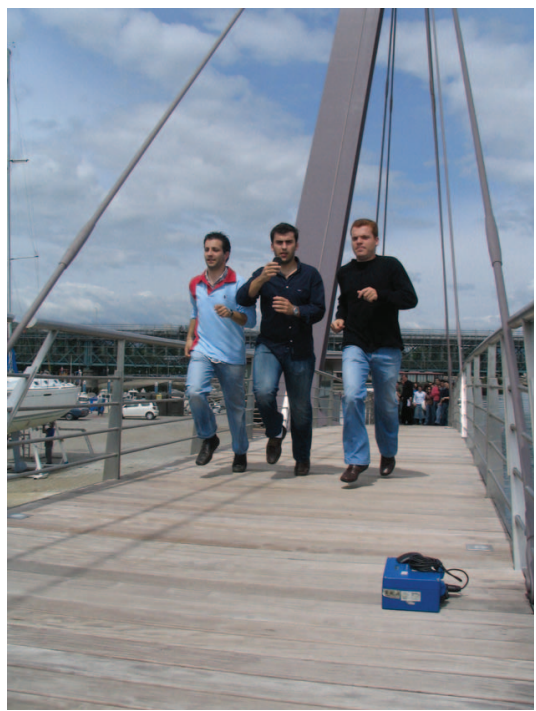

(c)

Figure 25. Images collected during dynamic tests for some of the considered load scenarios. Group of ten pedestrians running, group of six pedestrians jumping, group of three pedestrians running 
The Viana footbridge:

construction and dynamic

monitoring

Barbosa, Magalhães, Caetano and

Cunha

\begin{tabular}{lccc} 
Load type & $\begin{array}{c}\text { Pedestrian } \\
\text { numbers }\end{array}$ & $\begin{array}{c}\text { Frequency: } \\
\mathrm{Hz}\end{array}$ & $\begin{array}{c}\text { Maximum } \\
\text { acceleration: } \boldsymbol{g}\end{array}$ \\
\hline & 1 & & 0.15 \\
Running & 3 & $3 \cdot 10$ & 0.25 \\
& 10 & & 0.40 \\
& 20 & Free & 0.25 \\
& 30 & & 0.40 \\
& & 1.28 & 0.03 \\
Walking & & 1.38 & 0.03 \\
& 50 & 1.60 & 0.04 \\
& & 1.75 & 0.06 \\
Jumping & & 2.00 & 0.05 \\
(at section 4) & 11 & 2.50 & 0.07 \\
Forcing of cable & 2 & 3.10 & 0.35 \\
vibration & & 2.50 & 0.50 \\
& & & 0.25
\end{tabular}

Table 1. Synthesis of the results of the tests with groups of pedestrians

the context of running competitions) are, however, not acceptable on the bridge, as longer duration vibrations of very high amplitudes may occur. As for vandal actions, it is observed that a group of 11 persons jumping produces accelerations of $5 \mathrm{~m} / \mathrm{s}^{2}$. The direct excitation in resonance of one stay cable close to the anchorage by two single pedestrians has resulted in deck accelerations of $2 \cdot 5 \mathrm{~m} / \mathrm{s}^{2}$.

\subsection{Dynamic monitoring}

Considering the susceptibility of the footbridge to vertical induced vibrations, a simple monitoring programme was designed in order to assess the dynamic behaviour under normal service. For that purpose, a seismograph was placed inside a steel box under the timber surfacing, fixed to one of the main longitudinal beams (Figure 27). The instrumented section was chosen between the two pairs of longest stay cables, taking into account that it was important to monitor not only the vibration motivated by the pedestrians, but also the deck vibrations during the rotation operations or the vibration produced by the wind in the open position.

The seismograph was programmed to perform the acquisition of 15 min time series at the beginning of each hour. The bridge was monitored from $02 / 08 / 2007$ to $12 / 10 / 2007$ (summer/ autumn period) and from 11/12/2007 to 31/12/2007 (winter period), under the requirement of the bridge owner.

The graphic presented in Figure 28 shows the maxima observed in all the vertical acceleration time series collected from August to October. It can be observed that values above $1 \mathrm{~m} / \mathrm{s}^{2}(0 \cdot 1 \boldsymbol{g})$ are rare and that accelerations higher than $2 \mathrm{~m} / \mathrm{s}^{2}$ $(0 \cdot 2 \mathrm{~g})$ were never recorded. These results prove the good dynamic behaviour of the bridge under normal use.

The graphic presented in Figure 29 shows the maxima detected in all the lateral acceleration time series collected from August to October. Two bands of maxima are clearly observed. The higher band, corresponding to acceleration amplitudes close to $0 \cdot 3 \mathrm{~m} / \mathrm{s}^{2}$, is associated with the rotation operations. The lower band refers to the extreme values motivated by the pedestrian excitation (during the day) and by the wind (mainly during the night). Figure 30 presents one example of the time series of accelerations measured during a typical rotation operation (maximum lateral acceleration $0.3 \mathrm{~m} / \mathrm{s}^{2}$ ). The records are associated with the bridge opening to allow the entrance of a sailing boat into the marina. This operation takes approximately $1.5 \mathrm{~min}$.
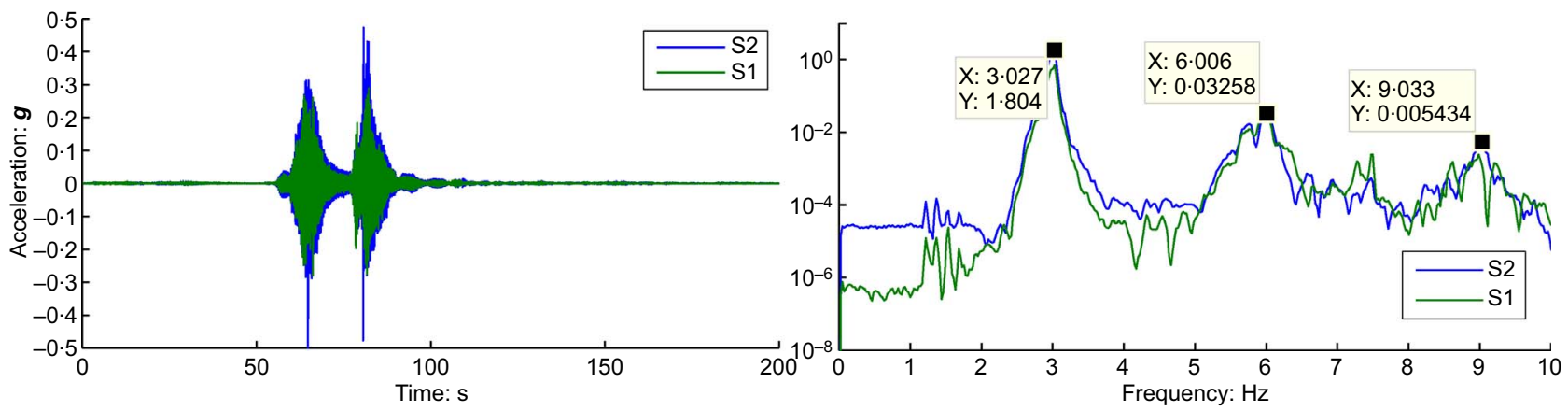

Figure 26. Time series and auto-spectra of the accelerations measured at sections 2 (S1) and 4 (S2) (Figure 3) during the crossing of the footbridge by 10 pedestrians running synchronously with a step frequency of $3 \cdot 10 \mathrm{~Hz}$ (go and return) 


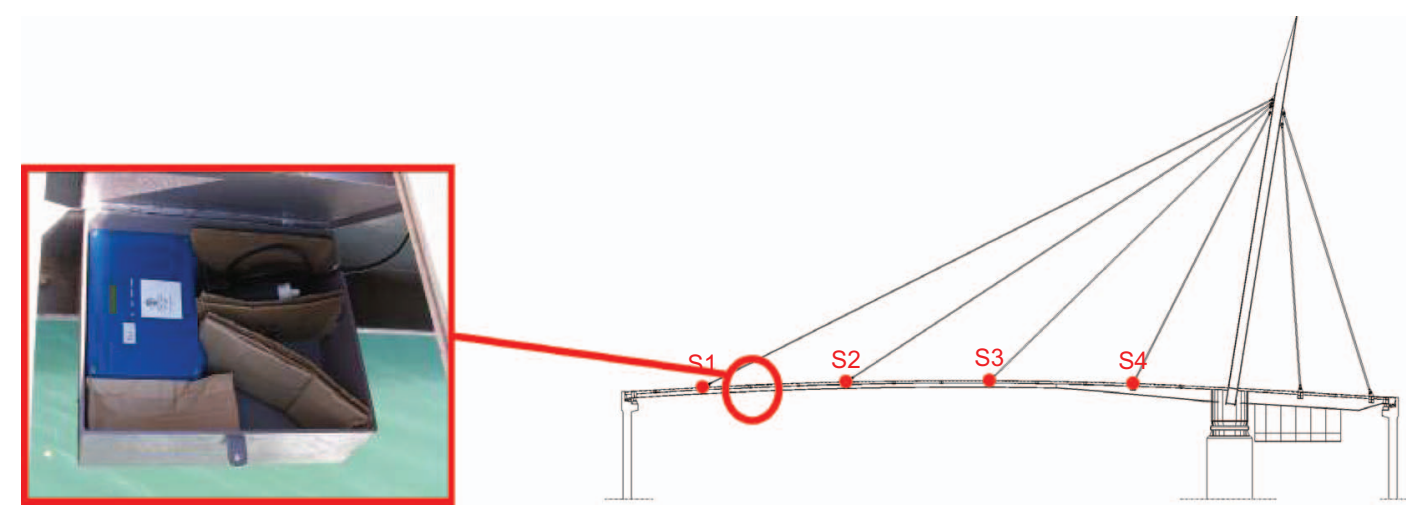

Figure 27. Installation of one seismograph under the bridge pavement

Besides the analysis of acceleration levels, the frequency content of all the time series collected during the monitoring period was also investigated. This last study was based on colour maps of the type of the one presented in Figure 31. This figure contains a top view (the colour is a function of the amplitude) of the auto-spectra of all the time series collected during the selected time period (03/08/2007 to 13/08/2007). Therefore, the presented figure is composed by $11 \times 24$ (number of days $\times 24 \mathrm{~h}$ ) auto-spectra.

As expected, the observed dominant frequencies during the night, in the open position, are completely different from those recorded during the day when the footbridge is normally closed and in use by pedestrians. During the night, the structure is only excited by the wind; while during the day (from 08:00 to
20:00 hours), it is mostly excited by pedestrians and by the wind.

During the night period, the dominant frequency is approximately $1 \mathrm{~Hz}$, corresponding to the first vertical bending mode of the bridge in the open position (Figure 21). The frequency observed in the finished bridge is slightly lower than that identified during the ambient vibration test, because the mass of the timber surfacing was added. In some periods the mode is more excited (red colour/dark), meaning that the wind is stronger during those setups.

During the day period, three natural frequencies stand out: $3 \mathrm{~Hz}, 6 \cdot 8 \mathrm{~Hz}$ and $7 \cdot 3 \mathrm{~Hz}$. These are associated with the same mode shapes that were identified in the second ambient

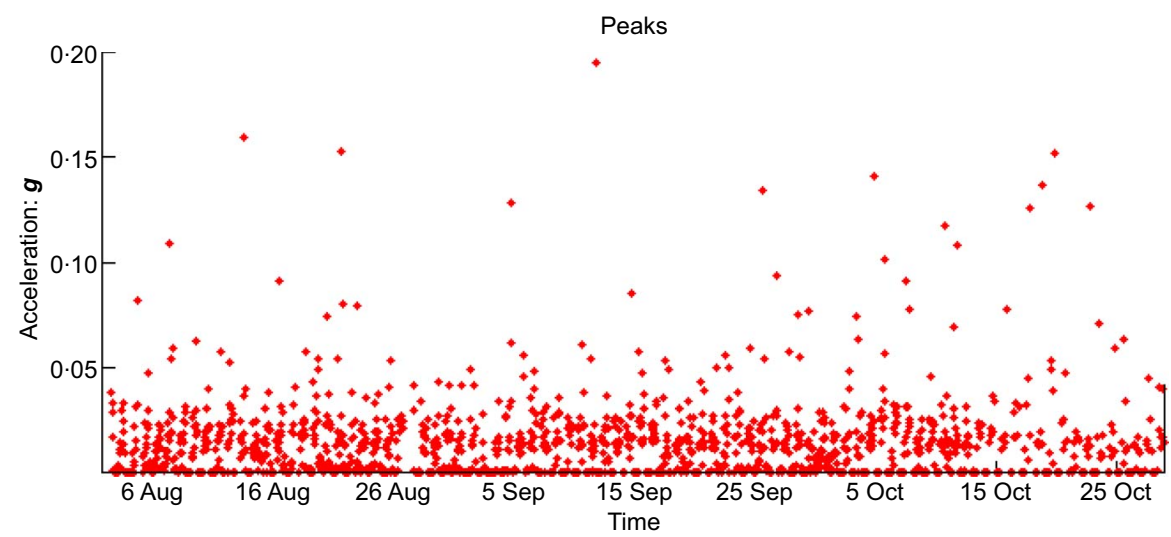

Figure 28. Maxima of the vertical acceleration time series collected between 02/08/2007 and 29/10/2007 


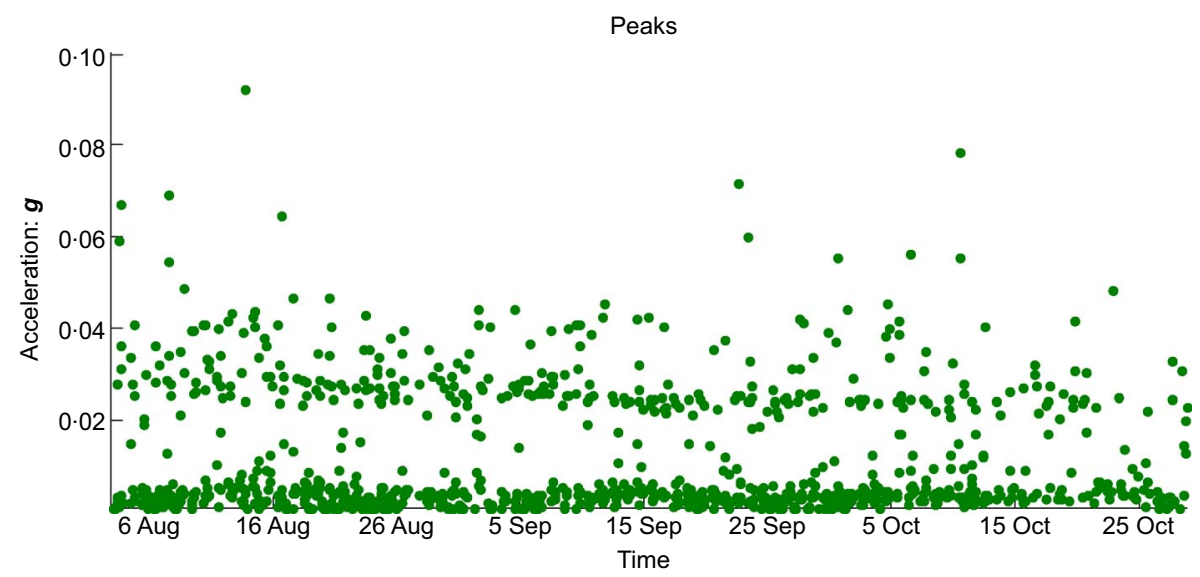

Figure 29. Maxima of the lateral acceleration time series collected between 02/08/2007 and 29/10/2007

vibration test (Figure 22). The level of energy associated with these modes depends on the number of pedestrians using the bridge, on their step frequency (closeness to the bridge natural frequencies) and on their degree of synchronisation.

The graphic presented at Figure 32 shows the evolution with time of the two first natural frequencies of the bridge. These were identified from the peaks of the auto-spectra of all collected time series. The estimates of the lower frequency (cantilever scenario) are very consistent, whereas those associated with the first frequency for the other structural configuration exhibit a higher scatter. This is a consequence of the frequency content associated with pedestrian excitation. Despite this fact, it is possible to observe that the mean value associated with both natural frequencies is approximately constant in time.
In addition to these main frequencies, several groups of vertical alignments can be identified in the colour map of Figure 31, especially concentrated in the range $1-2 \mathrm{~Hz}$. These are related to the stay cable natural frequencies. As a result, the analysis of the presented colour maps also allows the indirect detection of eventual sudden variations of cable forces.

The colour map of Figure 33 resumes the frequency content of the time series collected during the second half of December. The higher amount of energy observed on 19 December for the bridge first mode denotes the occurrence of strong winds. During the subsequent 2 days, wind velocities higher than $70 \mathrm{~km} / \mathrm{h}$ were observed and the bridge was closed as a precautionary measure during the night (in the colour map the first frequency in the open position is not observed on 20 and 21 December). In this last colour map, the energy content

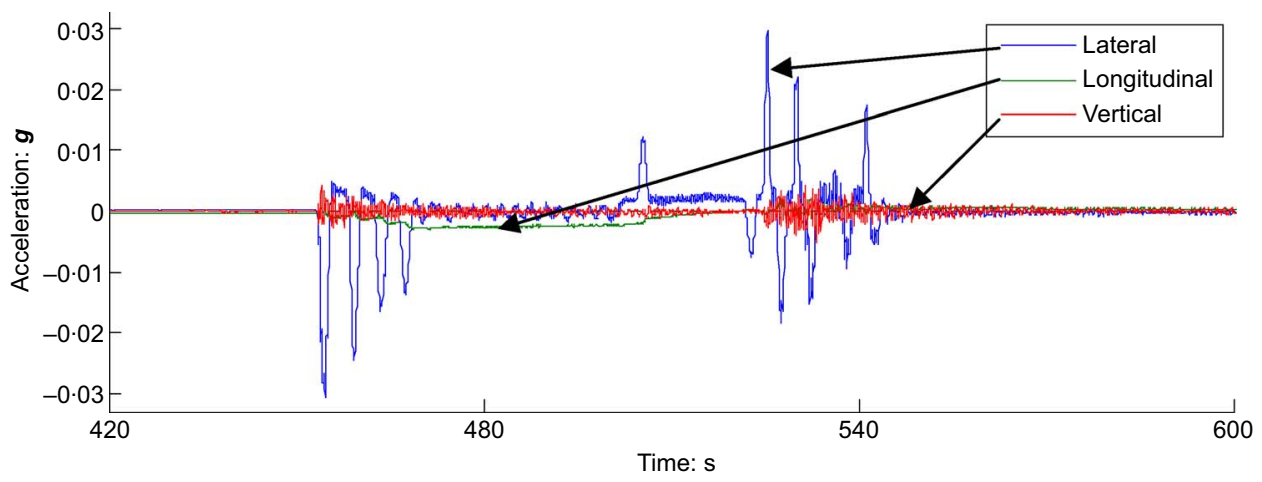

Figure 30. Time series collected during a rotation operation (from closed to open position) 
Bridge Engineering

Volume 166 Issue BE4
The Viana footbridge:

construction and dynamic

monitoring

Barbosa, Magalhães, Caetano and

Cunha

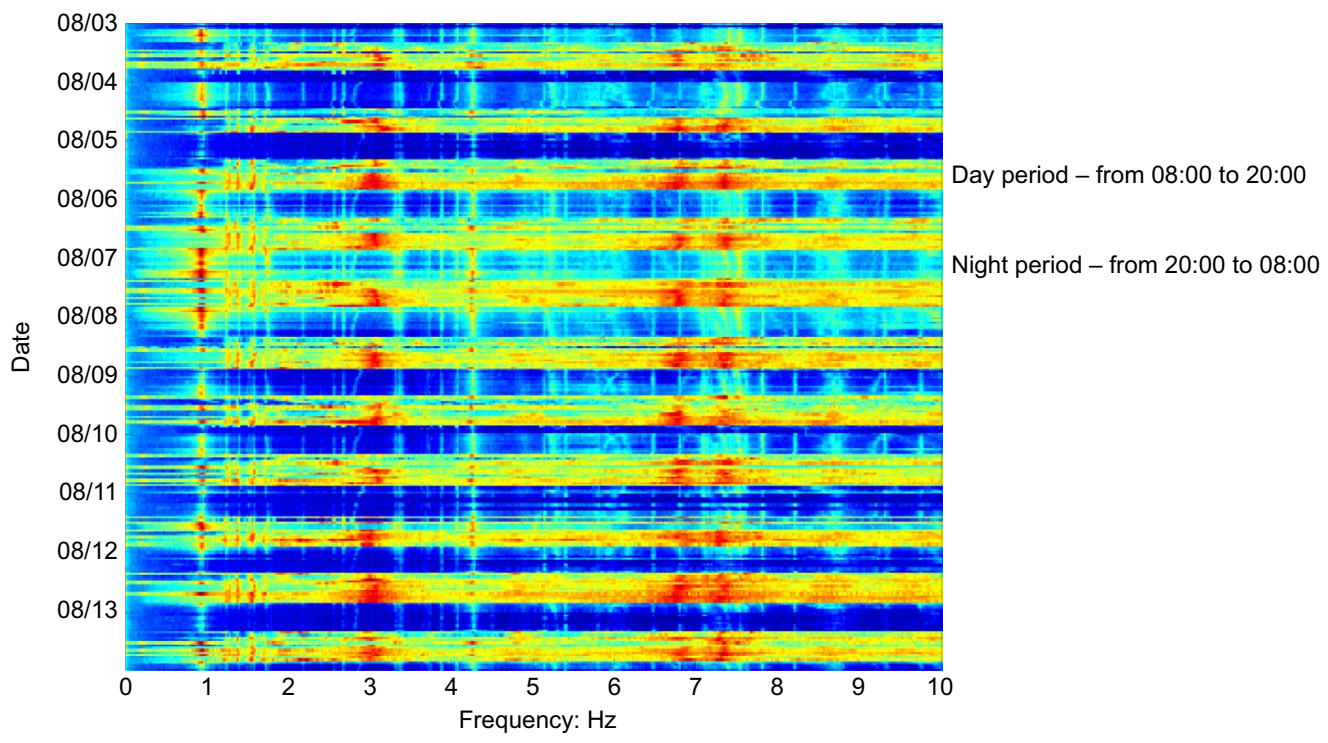

Figure 31. Colour map representing the frequency content of the time series collected from 03/08/2007 to 13/08/2007

associated with the $3 \mathrm{~Hz}$ frequency is lower than that related to the month of August, given that during the winter time fewer pedestrians use the bridge.

\section{Conclusions}

The paper describes the approach followed in the construction of a moveable footbridge at the entrance of a marina under operation. Despite the numerous difficulties related to the construction of a partly submersed foundation and with the mechanical implementation of an efficient rotating system, it was possible to minimise the impact of the works and the period of construction, which lasted 1 year.

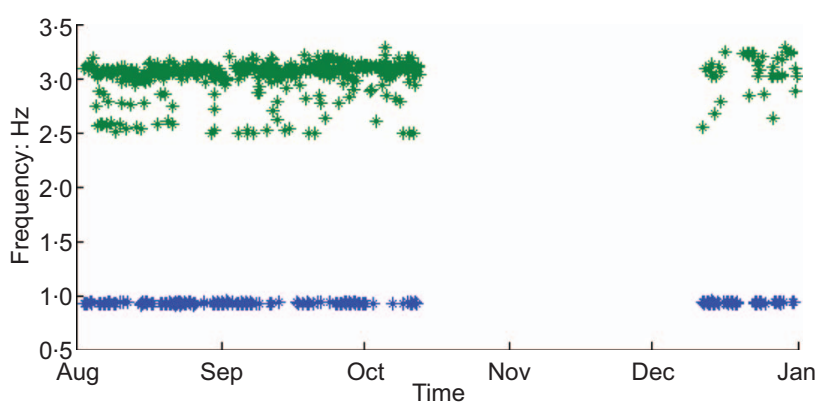

Figure 32. Evolution of the bridge first natural frequencies from 02/10/2007 to 31/12/2007: lower plot points (blue online) cantilever scenario; upper plot points (green online) bridge supported at the abutments
One of the aspects that caused some concern during construction was the lively behaviour of the bridge under pedestrian excitation. In this context, the dynamic tests and temporary continuous dynamic monitoring performed by VIBEST/FEUP at the request of the contractor played an essential role in terms of the characterisation of the real dynamic characteristics of the constructed structure, installed forces in the stay cables and levels of vibration under pedestrian use and during opening/closing operations. In particular, the monitoring of the bridge accelerations during a period of 4 months allowed the assessment of the

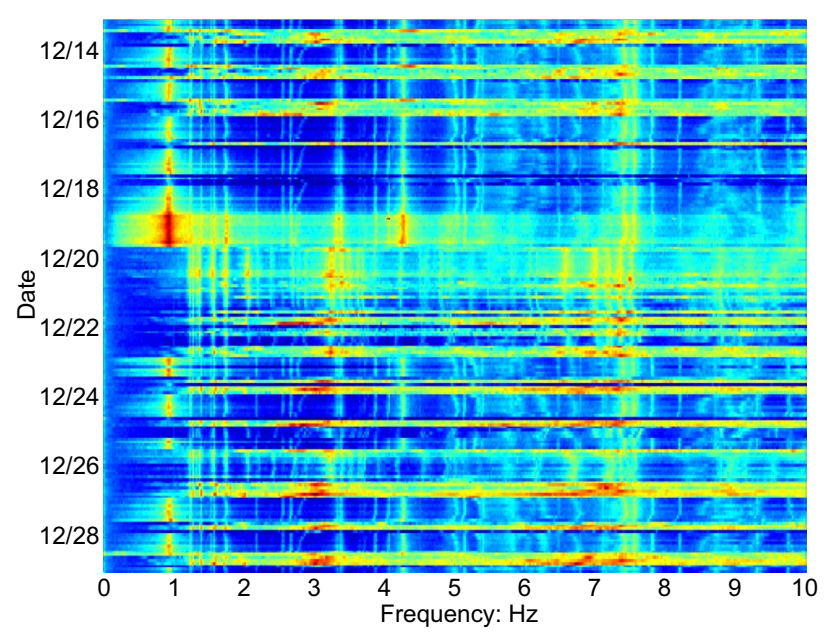

Figure 33. Colour map representing the frequency content of the time series collected from 13/12/2007 to 28/12/2007 
The Viana footbridge:

construction and dynamic

monitoring

Barbosa, Magalhães, Caetano and

Cunha comfort level of the footbridge under current use. Considering the limit acceleration ranges defined in the human-induced vibration of steel structures guidelines (HIVOSS, 2007) and the plot presented in Figure 28, it can be concluded that for the majority of the situations accelerations are well below $0.5 \mathrm{~m} / \mathrm{s}^{2}$, the limit for maximum comfort. In a small number of events amplitudes of vibration have attained $1 \mathrm{~m} / \mathrm{s}^{2}$, the limit for consideration of medium comfort. Vibrations in the range 1-2 $\mathrm{m} / \mathrm{s}^{2}$, associated with minimum comfort, have been measured more sporadically. Lateral vibrations are only relevant from the point of view of wind excitation in the open position and during opening/closing operations. The maximum values observed during the period of monitoring of the footbridge were approximately $0.9 \mathrm{~m} / \mathrm{s}^{2}$.

\section{Acknowledgements}

The authors would like to thank VianaPolis for permission to publish this paper. They wish to acknowledge the commitment of the construction company Irmãos Cavaco, SA in providing all the conditions for the realisation of dynamic tests and the installation of monitoring systems. They also acknowledge the technical support from Jorge Silva (mechanical engineer and production manager at Gustavo Cudell) concerning the oilhydraulics system, the collaboration of Professor Jorge Delgado and his students in the tests performed with groups of pedestrians, and the financial support provided by the Portuguese Foundation for Science and Technology (FCT) to VIBEST/CEC for the development of research in the area of dynamic tests on bridges.

\section{REFERENCES}

Bachmann H, Amman WJ, Deischl F et al. (1995) Vibration Problems in Structures. Practical Guidelines. Birkhäuser Verlag, Basel, Switzerland.

Caetano E, Cunha A and Taylor C (2000a) Investigation of dynamic cable-deck interaction in a physical model of a cable-stayed bridge. Part I: Modal analysis. International Journal of Earthquake Engineering and Structural Dynamics 29(4): 481-498.

Caetano E, Cunha A and Taylor C (2000b) Investigation of dynamic cable-deck interaction in a physical model of a cable-stayed bridge. Part II: Seismic response. International Journal of Earthquake Engineering and Structural Dynamics 29(4): 499-521.

Cunha A and Caetano E (2006) Experimental modal analysis of civil engineering structures. Sound and Vibration 6(40): 12-20.

Cunha A, Caetano E and Magalhães F (2007) Output-only dynamic testing of bridges and special structures, structural concrete. Journal of FIB 8(2): 67-85.

Delgado J, Delgado R, Lopes M, Gonçalves T and Lopes G (2008) A moveable footbridge at Viana do Castelo - Portugal. In Proceedings of the International Conference Footbridge, 2008, FEUP, Porto, Portugal.

HIVOSS (2007) Human induced vibration of steel structures guidelines. RFCS European Project. See http://www.stb. rwth-aachen.de/projekte/2007/HIVOSS/download.php (accessed 03/04/2012).

Irmãos Cavaco SA (2012) www.icsa.pt (accessed 03/04/2012). LABEST (2012) www.fe.up.pt/labest (accessed 03/04/2012). VIBEST (2012) www.fe.up.pt/vibest (accessed 03/04/2012).

\footnotetext{
WHAT DO YOU THINK?

To discuss this paper, please email up to 500 words to the editor at journals@ice.org.uk. Your contribution will be forwarded to the author(s) for a reply and, if considered appropriate by the editorial panel, will be published as discussion in a future issue of the journal.

Proceedings journals rely entirely on contributions sent in by civil engineering professionals, academics and students. Papers should be 2000-5000 words long (briefing papers should be 1000-2000 words long), with adequate illustrations and references. You can submit your paper online via www.icevirtuallibrary.com/content/journals, where you will also find detailed author guidelines.
} 